Board of Governors of the Federal Reserve System

International Finance Discussion Papers

Number 1304

October 2020

\title{
Technology, Geography, and Trade over Time: The Dynamic Effects of Changing Trade Policy
}

Carter Mix

Please cite this paper as:
Mix, Carter (2020). "Technology, Geography, and Trade over Time: The Dynamic Effects of
Changing Trade Policy," International Finance Discussion Papers 1304. Washington: Board
of Governors of the Federal Reserve System, https://doi.org/10.17016/IFDP.2020.1304.

NOTE: International Finance Discussion Papers (IFDPs) are preliminary materials circulated to stimulate discussion and critical comment. The analysis and conclusions set forth are those of the authors and do not indicate concurrence by other members of the research staff or the Board of Governors. References in publications to the International Finance Discussion Papers Series (other than acknowledgement) should be cleared with the author(s) to protect the tentative character of these papers. Recent IFDPs are available on the Web at www.federalreserve.gov/pubs/ifdp/. This paper can be downloaded without charge from the Social Science Research Network electronic library at www.ssrn.com. 


\title{
Technology, Geography, and Trade over Time: The Dynamic Effects of Changing Trade Policy
}

Carter Mixt

\begin{abstract}
I study the dynamic effects of changes in trade policy in a multi-country model with firms that make durable and destination-specific investments in exporting capacity. Using Mexican exporter-level data, I show that incumbent exporters to minor trade partners account for a smaller share of bilateral exports than do incumbent exporters to major trade partners, indicating a systematic difference in the persistence of the export decision across destinations. The model is calibrated to capture the positive relationship between exporting persistence and export volume, and predicts that trade liberalizations with minor export destinations deliver higher bilateral export growth than liberalizations with major export destinations. Panel analysis on bilateral exports after free trade agreements is consistent with these predictions, confirming that the model is a useful tool for explaining export behavior. Furthermore, I find that heterogeneity in export churning across destinations is a key driver of aggregate dynamics and welfare gains from changes in trade policy.
\end{abstract}

Keywords: trade policy, heterogeneous firms, export participation JEL classifications: F12, F13, F6.

*I am very grateful to my advisor, George Alessandria, for his guidance. I thank Will Johnson and Fernando Parro for excellent discussions of the paper. I also thank Yan Bai, Mark Bils, Lorenzo Caliendo, Jonathan Eaton, Doireann Fitzgerald, Narayana Kocherlakota, Logan Lewis, Dan Lu, Ricardo Reyes-Heroles, and Daniel $\mathrm{Xu}$ as well as audiences at Claremont McKenna College, the Federal Reserve Bank of Dallas, the Federal Reserve Board, Midwest Macro UGA, the Penn State New Faces in International Economics Conference, the Philadelphia Fed Trade Conference, the University of Western Ontario, and the Virtual International Trade and Macro Seminar for helpful comments. I'm also grateful to Andrea Garcia, who provided excellent research assistance. The views expressed in this paper are solely the responsibility of the authors and should not be interpreted as reflecting the views of the Board of Governors or of any other person associated with the Federal Reserve System. 


\section{Introduction}

International export markets exhibit little churning: in any given year, only a small fraction of exporters to a destination are new to the market, and those new exporters account for an even smaller fraction of export value. Low export churning is consistent with firms making durable investments in market access and has been a key factor in two-country models to explain the gradual response of trade to changes in trade policy and to evaluate dynamics in other aggregate variables (see, for example, Alessandria and Choi (2014)). The macroeconomic effects of destination-specific export churning in a multi-country setting have yet to be analyzed quantitatively. To perform such analysis, we must understand how export churning varies across destinations. In this paper, I use Mexican exporter-level data to document that heterogeneity in export churning across destinations is systematic: there is less churning in countries to which Mexico exports more.

To explain this phenomenon and to explore its effect on short-run and long-run dynamics, I develop a general equilibrum multi-country model with heterogeneous firms that make durable destination-specific investments in exporting capacity. The model captures existing facts about the importance of incumbent firms as well as the new fact regarding variation in churning across destinations. In addition, the model features endogenous capital accumulation, an internationally-traded noncontingent bond, free entry of firms in the domestic market, and capital-intensive trade, all important features for quantitative analysis. Although the model has many state variables, it remains quite tractable. As such, it is a tool that can be widely implemented to study the macroeconomic effects of trade policy over time.

In the model, all firms draw destination-specific fixed costs that must be paid in order to begin or continue exporting. A firm will export if the expected gain in firm value exceeds payment of the fixed cost, leading to an endogenous cutoff rule: firms that draw a fixed cost below the cutoff will export while firms that draw a fixed cost above the cutoff will not. The decision to export is dynamic since exporters and nonexporters to a destination draw their fixed costs from different distributions. In calibration, current exporters draw lower fixed costs than nonexporters on average, so choosing to export also makes a firm more likely to 
export in the next period, leading to the low churning we see in the data. Churning in all destinations is low, but it is higher in destinations where incumbents are more likely to draw a fixed cost above the threshold and stop exporting. Therefore, the cutoff thresholds for each destination and the shape of the fixed cost distributions determine the relationship between export churning and export volume.

Many multi-country models feature immediate adjustments in trade after changes in trade policy. The sunk nature of investments in exporting capacity in my model causes firms to enter or leave foreign markets slowly so that exports adjust gradually, as documented in the empirical literature. Because of the variation in export churning across destinations, the model predicts that bilateral export responses vary after changes in policy. Minor export destinations have more churning, so the adjustment in the extensive margin of trade is both faster and larger. In a simulated global liberalization, the calibrated model predicts that bilateral exports to minor export partners grow faster in the first 10 years and exhibit higher long-run growth than exports to major export partners.

I use bilateral trade and free trade agreement data to test these predictions. The data resemble that of Baier and Bergstrand (2007), but the estimation includes an interaction term that accounts for whether the free trade agreement partner is a major export destination. The results confirm that after a free trade agreement, exports to minor export partners grow more both in the short run and in the long run. Wald tests on both results yield significance at the $1 \%$ level. I conclude that the model captures export behavior better than existing multi-country models, which predict similar export responses to all destinations.

The model has important implications for welfare and aggregate dynamics after a liberalization in trade. I recalibrate initial tariffs to roughly match tariffs in the data as of 2014 and simulate a global liberalization that eliminates them. Regions like East Asia or China that depend heavily on trade and have high initial tariffs on incoming or outgoing goods experience the largest welfare gains, generally around 2 percent. Countries like the U.S., Canada, or Mexico that are either more closed or have low initial tariffs have smaller welfare gains, around 0.5 percent. Because countries take time to accumulate capital and increase trade, the gains from trade are backloaded. In the short run, countries with larger gains borrow against future income from countries with smaller gains. After the liberalization, the 
U.S. is predicted to increase its net foreign asset (NFA) position by about 6 percent of GDP in the long run while China is expected to decrease its NFA position by 9.5 percent of GDP.

The heterogeneity in churning across destinations and the dynamic exporting decision are key drivers of aggregate dynamics and welfare gains. A model calibrated to match all the same moments but with uniform churning across destinations delivers smaller welfare gains and a slower and smaller trade response. A static exporter model yields similar welfare gains as the benchmark model, but the sources and timing of the gains in the two models are very different. The model's ability to explain trade dynamics and their effects on other aggregate variables makes it a useful tool to analyze the short-run and long-run effects of changes in trade policy.

\section{$1.1 \quad$ Related literature}

The model relates to three branches in the literature: static trade, dynamic trade, and international real business cycles (IRBC). The static trade literature embodies the prevailing modus operandi for studying the aggregate effects of trade policy in a multi-country setting. A seminal paper is Eaton and Kortum (2002) (EK), which introduces a static model of trade in which real-world asymmetries in size and trade flows can easily be modeled and illustrates how this heterogeneity matters for the effects of trade policy. Since then, several variations of the model have been developed to explore heterogeneity in the gains from trade across sectors, workers, regions, etc. Analysis of policy in these models is performed by considering two equilibria under different policy regimes, with no notion of time or a transition of the economy!

The IRBC literature studies aggregate fluctuations in an open economy. IRBC models generally include dynamic elements from the macroeconomics literature such as capital or trade in assets. Backus et al. (1992) introduce capital and financial markets between countries into an otherwise Armington-type model and find that the model can capture several empirical regularities in the data. Several papers incorporate IRBC dynamics into an EK

\footnotetext{
${ }^{1}$ See, for example, Caliendo and Parro (2015). Extensions of the EK framework have also been used to study other types of dynamics such as labor market dynamics, which are not addressed in this paper. Papers include Caliendo et al. (2019) and Dix-Carneiro (2014).
} 
model. Alvarez (2017), Eaton et al. (2016), and Ravikumar et al. (2019) show that endogenous capital accumulation generates larger gains from trade than a purely static model. Eaton et al. (2016), Fitzgerald (2012), Ravikumar et al. (2019), and Reyes-Heroles (2016) incorporate financial markets into an EK model. All these papers abstract from heterogeneous firms and firm dynamics and predict a static trade response to changes in trade policy that is similar for all destinations, leading to different aggregate dynamics than are predicted by the model in this paper.

The dynamic trade literature includes both empirical and quantitative studies on the effects of trade policy and trade costs on trade over time. Empirical work by Baier and Bergstrand (2007) and Jung (2012) argue that the increases in trade from trade agreements are large but take several years to materialize. Das et al. (2007) find evidence that firms pay large "sunk costs" to produce in foreign markets which generate exporter hysteresis as in a series of papers by Baldwin, Dixit, and Krugman. Furthermore, recent work by McCallum (2015), Monarch and Schmidt-Eisenlohr (2017), and Morales et al. (2019) implies that sunk costs are not global but destination-specific. Ghironi and Melitz (2005) and Ghironi and Melitz (2007) consider the importance of firm dynamics for aggregate outcomes in a two-country model of trade where export entry costs are static. Alessandria and Choi (2007) add a global sunk cost into a two-country Melitz-type (Melitz (2003)) general equilibrium heterogeneous firm model of trade to generate a dynamic trade elasticity. Alessandria and Choi (2014) use the same sunk cost and show that a dynamic trade elasticity changes the macroeconomic effects of trade policy. The models with dynamic trade elasticities are generally confined to only two symmetric countries, ignoring the impact of cross-sectional heterogeneity and making analysis of many multilateral trade policies impossible. An important exception is Steinberg (2019) who introduces a three country model of exporting to analyze the impact of Brexit and trade uncertainty on the UK. The focus of my model is instead the importance of firm-level churning across destinations on aggregate outcomes. 


\section{Micro Data - Destination-level export churning}

I use data on Mexican exporters from 2000 to 2009 from the World Bank Exporter Dynamics Database (see Fernandes et al. (2016)). The data includes the destination-specific export values for all exporters in Mexico from 2000 to 2009. Using these data, I confirm that exporting is persistent at the destination level. I also document that persistence varies systematically across destinations. Destinations to which Mexico exports more exhibit more persistent exporting by incumbents. In other words, there is less export churning with closer trade partners. These two facts are the basis of the calibration in the model.

\subsection{Exporting is persistent at the destination level}

Consider two measures of the importance of incumbent exporters in a destination. The incumbent exporter share for destination $d$ in year $t i n c_{d t}^{n}$ is the share of exporters to $d$ in year $t$ that are incumbents (current exporters to $d$ that also exported to $d$ in year $t-1$ ). The incumbent export share $i n c_{d t}^{x}$ is the share of exports to $d$ in year $t$ sent by the incumbent exporters.

The average incumbent share across all Mexican destinations is obtained by taking an export-weighted average of the destination-year incumbent share across all countries and years.$^{2}$ On average, 59 percent of exporters to a destination were incumbents from 2001 to 2009. Unless the fraction of Mexican firms exporting to a single destination is close to 59 percent, which is unlikely, the incumbent exporter share tells us that current exporters to a destination are more likely than nonexporters to export to the same destination next year, meaning that the export decision is persistent.

The incumbent export share is much higher than the incumbent exporter shares, averaging 96 percent over all years and destinations. The higher incumbent export share is consistent with empirical work such as Ruhl and Willis (2017) that show exporters take time to grow in foreign markets so incumbents export more than new exporters. The incumbent export share tells us that in any given year, the contribution of new exporters to changes in

\footnotetext{
${ }^{2}$ I remove destinations that receive fewer than 1 million U.S. dollars' worth of exports from Mexico in any given year. All results in this section are robust to including these firms in the analysis.
} 
total exports is small. In the quantitative literature, the contribution of new exporters to total exports is a key moment to explain aggregate trade responses (see Alessandria et al. (2018)).

\subsection{Exporter persistence across destinations}

We now know that average export churning is low at the destination level. But does export churning vary systematically across destinations? The scatter plots in Figure 1 show the incumbent shares for each destination export-weighted over all years relative to the average logged exports to that destination over the same years. The positive relationship between persistence and export volume for both measures is apparent.

To show the relationship more generally, I regress the destination-year incumbent shares on logged bilateral exports

$$
i n c_{d t}=\ln e x_{d t}+\varepsilon_{d t} .
$$

Table 1 reports the regression results in columns 1 and 5. A 100 log point increase in exports increases the incumbent exporter share by 1.2 percentage points and the incumbent export share by 3.8 percentage points. Taking a destination from the 25 th percentile of total exports to the 75 th percentile is predicted to increase the incumbent exporter share from 49.8 percent to 53.5 percent and the incumbent export share from 75 percent to 86.7 percent.

The positive relationship between incumbent shares and export volume is robust to including year fixed effects as seen in columns 2 and 6 . The incumbent export share also responds to changes in exports within a destination across time as evidenced by the positive and significant coefficient in the regression with destination and year fixed effects in column 7. Increasing exports to a destination by $10 \log$ points from one year to the next increases the incumbent export share by roughly 0.3 percentage points on average.

The results are also robust to excluding the smallest exporters in any destination. One might think that the high churning in minor export partners is because some small firms export there by chance for one year, never expecting to continue exporting. To address this issue, I only count a firm as an exporter to a destination if it exports more than some threshold value. I use thresholds of $\$ 1,000, \$ 10,000, \$ 100,000$, and $\$ 1,000,000$. In all cases, 
the relationship between persistence and export volume is positive and significant. In fact, as the threshold grows, the coefficients of the regression grow as well (results for a threshold of $\$ 100,000$ with no fixed effects are shown in Table 11.

The Exporter Dynamics Database (EDD) includes summary statistics on destinationspecific export markets for several countries. I chose Mexico as the main country for analysis because it is the most-developed country in the database for which exporter-level data is available to perform my own calculations. However, the results presented in this section are confirmed in a large panel using the summary statistics of all countries in the EDD, which includes other developed countries such as Belgium, Chile, Denmark, Germany, Portugal, South Africa, Spain, Sweden, and Turkey, and many less developed countries. Results from the panel data can be found in Appendix C.

The high persistence in destination-specific exporting and the positive relationship between persistence and export volume will be key features to capture in the model.

\section{Model}

Now we turn to the details of the model. The model has $I$ regions and each region comprises $J_{i} \geq 1$ identical countries. By having multiple identical countries within a region, the model can account for average policy changes and reliance on trade for countries in a region without modeling each country explicitly. These factors matter for borrowing and lending incentives after trade policy changes because they influence the expected path of output and consumption. I denote country variables such as consumption with a hat $\hat{C}_{i}$ and region variables without a hat $C_{i}$. Because countries are identical, we have $\hat{C}_{i}=C_{i} / J_{i}$. I ignore the hats for prices as identical countries have identical prices for all commodities.

\subsection{Consumers}

A representative consumer in each country $i$ chooses consumption $\hat{C}_{i}$, labor $\hat{L}_{i}$, investment in

physical capital $\hat{X}_{i}$, and holdings of a risk-free bond $\hat{B}_{i}^{\prime}$ to maximize welfare. The recursive 
value function of country $i$ 's consumer is

$$
V^{C}\left(\hat{K}_{i}, \hat{B}_{i}, S\right)=\max _{\hat{C}_{i}, \hat{L}_{i}, \hat{X}_{i}, \hat{B}_{i}^{\prime}} \frac{1}{1-\sigma}\left[\hat{C}_{i}^{\mu}\left(\hat{\bar{L}}_{i}-\hat{L}_{i}\right)^{1-\mu}\right]^{1-\sigma}+\beta V^{C}\left(\hat{K}_{i}^{\prime}, \hat{B}_{i}^{\prime}, S^{\prime}\right)
$$

subject to a budget constraint and the law of accumulation for capital

$$
\begin{aligned}
P_{C i} \hat{C}_{i}+P_{X i} \hat{X}_{i}+Q \hat{B}_{i}^{\prime} & \leq W_{i} \hat{L}_{i}+R_{i} \hat{K}_{i}+\hat{B}_{i}-\frac{\phi J_{i}}{2}\left(\hat{B}_{i}^{\prime}-\hat{\bar{B}}_{i}\right)^{2}+\hat{\Pi}_{i}+\hat{T}_{i} \\
\hat{K}_{i}^{\prime} & =\hat{X}_{i}+(1-\delta) \hat{K}_{i}
\end{aligned}
$$

where $S$ is the aggregate state variable; $\hat{\bar{L}}_{i}$ is the population; $P_{i}$ and $P_{X i}$ are the prices of the consumption and investment final goods; $W_{i}$ and $R_{i}$ are the wage and rental price of capital; $Q$ is the world price of the bond denominated in the numeraire; $\hat{K}_{i}$ is today's stock of capital; $\hat{\Pi}_{i}$ is the profits from intermediate firms; $\hat{T}_{i}$ is a lump sum transfer from tariff revenue; $\delta$ is the depreciation rate; $1 / \sigma$ is the intertemporal elasticity of substitution; and $\mu$ determines the relative preference between consumption and leisure in utility. A small adjustment costs on bond holdings, $\left(\phi J_{i} / 2\right)\left(\hat{B}_{i}^{\prime}-\hat{\bar{B}}_{i}\right)^{2}$, is introduced for computational reasons.

The solution to the problem includes an intratemporal condition for labor

$$
\frac{U_{C}}{P_{C}} W=U_{L}
$$

and two intertemporal conditions for investment in capital and the risk free bond

$$
\begin{aligned}
& \frac{U_{C}}{P_{C}} P_{X}=\beta \mathbb{E} \frac{U_{C^{\prime}}}{P_{C}^{\prime}}\left[R^{\prime}+P_{X}^{\prime}(1-\delta)\right] \\
& \frac{U_{C}}{P_{C}} Q=\beta \mathbb{E} \frac{U_{C^{\prime}}}{P_{C}^{\prime}}\left[1-\phi\left(\hat{B}^{\prime}-\hat{\bar{B}}\right)\right]
\end{aligned}
$$

where $U_{x}$ denotes the derivative of the utility function with respect to $x$. In simulations, $\bar{B}$ may change in response to a trade policy change. The nominal price of the bond $Q_{t}$ and therefore the nominal return on the bond $1 / Q_{t}$ is the same across all countries. The real interest rate on the bond varies across countries in transition depending on differences in price movements. In calibration, the price of the consumption good in the U.S. will be the numeraire.

\subsection{Final Goods Producers}

A continuum of competitive final goods producers in each country combine home and foreign intermediates and home labor to produce consumption, investment, and material goods. The 
production technology differs for each type of good. Let $G$ be any good in $\{C, X, M\}$ where $M$ stands for material goods. Let $\hat{G}_{j i}$ be region $j$ 's exports to a single country in region $i$, $\hat{G}_{T i i}$ be a country in region $i$ 's imports from all other countries in region $i$, and $\hat{G}_{N T i i}$ be the domestically produced intermediates that will be used to produce good $G$. Production of $\hat{G}_{i}$ is Cobb-Douglas between a bundle of intermediates $\hat{\tilde{G}}_{i}$ and domestic labor $\hat{L}_{G i}$

$$
\hat{G}_{i}=\hat{\tilde{G}}_{i}^{\alpha_{G}} \hat{L}_{G i}^{1-\alpha_{G}}
$$

where $\alpha_{G}$ is the share of input spending on the intermediate bundle and varies across final goods to account for differences in gross output to value added in the data for consumption, investment, and intermediates.

The intermediate bundle is a CES aggregate of imports from individual countries

$$
\begin{aligned}
\hat{\tilde{G}}_{i} & =\left[\sum_{j \neq i} J_{j}\left(\frac{\hat{G}_{j i}}{J_{j}}\right)^{\frac{\gamma-1}{\gamma}}+\left(J_{i}-1\right)\left(\frac{\hat{G}_{T i i}}{J_{i}-1}\right)^{\frac{\gamma-1}{\gamma}}+\hat{G}_{N T i i}^{\frac{\gamma-1}{\gamma}}\right]^{\frac{\gamma}{\gamma-1}} \\
& =\left[\sum_{j \neq i} J_{j}^{\frac{1}{\gamma}} \hat{G}_{j i}^{\frac{\gamma-1}{\gamma}}+\left(J_{i}-1\right)^{\frac{1}{\gamma}} \hat{G}_{T i i}^{\frac{\gamma-1}{\gamma}}+\hat{G}_{N T i i}^{\frac{\gamma-1}{\gamma}}\right]^{\frac{\gamma}{\gamma-1}}
\end{aligned}
$$

where $\gamma$ is the elasticity of substitution between bundles of intermediates from different countries. Imported and domestic bundles are themselves CES aggregates of imports from individual firms $\hat{G}_{j i}(f)$

$$
\hat{G}_{j i}=\left[\int_{f \in \Omega_{j i}} \hat{G}_{j i}(f)^{\frac{\theta-1}{\theta}}\right]^{\frac{\theta-1}{\theta}}
$$

where $\Omega_{j i}$ is the set of firms in region $j$ that produce for region $i$ and $\theta$ is the elasticity of substitution between intermediate goods within the same country. Bundles of within region imports $\hat{G}_{T i i}$ and domestic intermediates $\hat{G}_{N T i i}$ are similarly defined.

A final goods producer in country $i$ chooses inputs for good $G$ to maximize current profits

$$
\begin{aligned}
\pi_{G i}= & \max P_{G i} \hat{G}_{i}-\sum_{j \neq i} \tau_{j i} \int_{f \in \Omega_{j i}} P_{G j i}(f) \hat{G}_{j i}(f) d f-\tau_{i i} \int_{f \in \Omega_{T i i}} P_{G T i i}(f) \hat{G}_{T i i}(f) d f \\
& -\int_{f} P_{N T i i}(f) \hat{G}_{N T i i}(f) d f
\end{aligned}
$$

subject to the production and aggregation technologies. $\tau_{j i}$ is the tariff applied on goods imported by a country in region $i$ from any country in region $j, P_{G j i}(f)$ is the price of intermediate goods destined for good $G$ production imported by a country in region $i$ from 
firm $f$ in region $j, P_{G T i i}(f)$ is the firm $f$ price of intermediates traded between countries in region $i$, and $P_{N T i i}(f)$ is the domestic firm $f$ price of intermediates which is the same for all final goods.

Demand for bundles of intermediates is

$$
G_{j i}=\left(\frac{\tau_{j i} P_{G j i}}{\tilde{P}_{G i}}\right)^{-\gamma} J_{j} \tilde{G}_{i} \quad G_{T i i}=\left(\frac{\tau_{i i} P_{G T i i}}{\tilde{P}_{G i}}\right)^{-\gamma}\left(J_{i}-1\right) \tilde{G}_{i} \quad G_{N T i i}=\left(\frac{P_{N T i i}}{\tilde{P}_{G i}}\right)^{-\gamma} \tilde{G}_{i}
$$

and demand for imports from individual firms is

$$
\begin{aligned}
& G_{j i}(f)=\left(\frac{P_{G j i}(f)}{P_{G j i}}\right)^{-\theta} G_{j i} \quad G_{T i i}(f)=\left(\frac{P_{G T i i}(f)}{P_{G T i i}}\right)^{-\theta} G_{T i i} \\
& G_{N T i i}(f)=\left(\frac{P_{N T i i}(f)}{P_{N T i i}}\right)^{-\theta} G_{N T i i} .
\end{aligned}
$$

The hats have been removed because the equations are the same without them.

The aggregate price of intermediates for good $G \tilde{P}_{G i}$ and the bundle prices $P_{G j i}, P_{G T i i}$ and $P_{N T i i}$ take the usual Dixit-Stiglitz forms

$$
\begin{aligned}
\tilde{P}_{G i}^{1-\gamma} & =\sum_{j \neq i} J_{j}\left(\tau_{j i} P_{G j i}\right)^{1-\gamma}+\left(J_{i}-1\right)\left(\tau_{i i} P_{G T i i}\right)^{1-\gamma}+P_{N T i i}^{1-\gamma} \\
P_{G j i}^{1-\theta} & =\int_{f \in \Omega_{j i}} P_{G j i}(f)^{1-\theta} d f \\
P_{G T i i}^{1-\theta} & =\int_{f \in \Omega_{T i i}} P_{G T i i}(f)^{1-\theta} d f \\
P_{N T i i}^{1-\theta} & =\int_{f} P_{N T i i}(f)^{1-\theta} d f .
\end{aligned}
$$

The aggregate price of final good $\mathrm{G} P_{G i}$ is a function of the price of the intermediate bundle $\tilde{P}_{G i}$ and the wage $W_{i}$.

\subsection{Intermediate Goods Producers}

Each country has a continuum of monopolistically competitive firms that use physical capital $k$, domestic labor $l$, and materials $m$ to produce intermediate goods. All of the firms sell in their domestic market, but firms can also decide to sell in foreign markets. Each year, firms draw a fixed cost for each destination that they must pay to export to that market in the next

year. Current exporters to a destination draw their fixed cost for that destination from a distribution that is first order stochastic dominated by the current nonexporter distribution. 
Thus, current exporters draw lower fixed costs for that destination on average, and are more likely to export the following year than current nonexporters. Exporters decide to export by region, not country. The setup of the intermediate goods producers' problem is similar to Alessandria et al. (2013), but extended to general equilibrium and to include many regions.

Firms choose their inputs, prices $p_{G j}$ and $p_{N T}$, and future export status $e_{j}^{\prime}$ to maximize the expected discounted value of their profits. Firms are distinguished at the start of the year by their export status vector $e_{I \times 1}$ and their fixed cost draws $\kappa_{I \times 1}$ which are drawn from distribution $F_{e_{j}}(\kappa)$ for each destination $j$. The value function for an intermediate goods producer in country $i$ is

$$
\begin{gathered}
V\left(e, \kappa ; F_{e}\right)=\max _{e^{\prime}, p_{G j}, l, k, m, p_{N T}}\left[\sum_{j \in I} e_{i j} \sum_{G} p_{G j} G_{i j}(f)-W_{i} e_{j}^{\prime} \kappa_{j}\right]+p_{N T} \sum_{G} G_{N T i i}(f) \\
-W_{i} l-R_{i} k-P_{M i} m+n_{s} \mathbb{E} D_{t} V\left(e^{\prime}, \kappa^{\prime} ; F_{e^{\prime}}\right)
\end{gathered}
$$

subject to demand from the final goods producers and a production constraint

$$
\sum_{G}\left(\sum_{j \in I} \xi_{G i j} G_{i j}(f)\right)+G_{N T i i}(f)=z_{i}\left(k^{\alpha} l^{1-\alpha}\right)^{1-\alpha_{m}} m^{\alpha_{m}}
$$

where $n_{s}$ is the constant probability of survival,

$$
D_{t}=\frac{U_{C, t+1}}{U_{C, t}} \frac{P_{C, t}}{P_{C, t+1}}
$$

is the subjective discount factor, $\xi_{i j G}$ is the good G-specific iceberg cost on intermediates goods shipped from region $i$ to region $j, z_{i}$ is the productivity of all firms in region $i$, and $\alpha$ and $\alpha_{m}$ are Cobb-Douglas parameters in production.

The only source of heterogeneity between firms within a region is their fixed cost draws. In particular, all firms within a region have the same productivity. That firms all share the same productivity is consistent with the original EK framework and many that have followed. The difference in this model is that firms choose whether to export based on fixed cost draws and are monopolistically competitive.

Alternatively one could make firms heterogeneous in productivity but have exogenous sunk and continuation costs for each foreign market. However, the current setup has two distinct advantages. First, the model with heterogeneous productivity would exhibit hierarchical exporting for firms. For example, the model would say that any U.S. firm productive 
enough to export to Russia must also export to Canada. With heterogeneous fixed costs, draws for different destinations are independent and firms can sell in any combination of countries, as in the data. Second, the high sunk cost and low continuation cost in the heterogeneous productivity model means that entering exporters are, on average, more productive and export more than incumbent exporters so the contribution of new exporters to total exports is high. We know that the opposite is true in the data (see Ruhl and Willis (2017)). With identical productivity, new and incumbent exporters export the same amount and exporter entry can be calibrated to match the contribution of new exporters to total exports.

The optimal price of goods in the domestic market is a familiar constant markup over marginal cost

$$
p_{N T}=\frac{\theta}{\theta-1} M C_{i}=\frac{\theta}{\theta-1} \frac{1}{z_{i}}\left(\frac{P_{M i}}{\alpha_{m}}\right)^{\alpha_{m}}\left[\frac{\left(\frac{R_{i}}{\alpha}\right)^{\alpha}\left(\frac{W_{i}}{1-\alpha}\right)^{1-\alpha}}{1-\alpha_{m}}\right]^{1-\alpha_{m}}
$$

and the price in foreign markets is scaled by the iceberg cost $p_{G j}=\xi_{G i j} p_{N T}$. Inputs of capital, labor, and materials are chosen so that a constant share of firm expenditure is on each input, as dictated by the Cobb-Douglas shares in the production function. The decision to export is dynamic as today's decision affects future profits.

\subsubsection{Dynamic exporting decision}

A firm with exporting status $e_{j} \in\{0,1\}$ to destination $j$ draws the fixed cost to export to $j$ tomorrow from a Generalized Pareto distribution

$$
F_{e_{j}}(\kappa)=1-\left(1+\frac{v \kappa}{f_{e_{j}}}\right)^{-\frac{1}{v}}
$$

where $f_{e_{j}}$ is a scale parameter and $v$ is a shape parameter. Given $v<1$, the expected draw for a firm with status $e_{j}$ is $f_{e_{j}} /(1-v)$. When $f_{1}<f_{0}$, the export decision is forward looking. Paying the fixed cost today gives the firm access to the foreign market tomorrow and makes it more likely to have access to the same market in the next period. Because production of the intermediate good is constant returns to scale and all inputs are adjustable, we can consider the firm's export decision separately for each destination.

Let $\pi^{*}$ be the optimal static profits of a firm in a foreign destination if it is currently 
exporting. The decision to export next year for a firm with current export status $e \in\{0,1\}$ and fixed cost draw $\kappa$ can be written as

$$
V_{e}(\kappa)=\max \left\{e \pi^{*}-W \kappa+n_{s} \mathbb{E} D V_{1}\left(\kappa^{\prime}\right), e \pi^{*}+n_{s} \mathbb{E} D V_{0}\left(\kappa^{\prime}\right)\right\} .
$$

The firm will export next year if and only if $\kappa$ is below a threshold fixed cost $\kappa^{*}$ with

$$
\kappa^{*}=\frac{n_{s} \mathbb{E} D\left[V_{1}\left(\kappa^{\prime}\right)-V_{0}\left(\kappa^{\prime}\right)\right]}{W} .
$$

The difference $V_{1}(\kappa)-V_{0}(\kappa)$, whose expectation determines the threshold fixed cost for exporting, is

$$
V_{1}(\kappa)-V_{0}(\kappa)=\pi^{*}-W \int_{0}^{\kappa^{*}} \kappa\left[d F_{1}(\kappa)-d F_{0}(\kappa)\right]+n_{s} \mathbb{E} D\left[\left[F_{1}\left(\kappa^{*}\right)-F_{0}\left(\kappa^{*}\right)\right]\left[V_{1}\left(\kappa^{\prime}\right)-V_{0}\left(\kappa^{\prime}\right)\right]\right] .
$$

That is, current exporters earn profits $\pi^{*}>0$ not earned by nonexporters, draw lower fixed costs (but have a higher probability of paying them), and are more likely to export in the next period. Rewriting this equation in steady state, we have

$$
V_{1}(\kappa)-V_{0}(\kappa)=\frac{\pi-W \int_{0}^{\kappa^{*}} \kappa\left[d F_{1}(\kappa)-d F_{0}(\kappa)\right]}{1-n_{s} \beta\left[F_{1}\left(\kappa^{*}\right)-F_{0}\left(\kappa^{*}\right)\right]} .
$$

In words, an exporter in steady state is better off than a nonexporter by the expected discounted value of profits and the difference in average payments of the fixed costs.

\subsubsection{Free Entry}

Intermediate goods producers die with probability $1-n_{s}$ in each period. New firms can pay a fixed cost $f_{e}$ denominated in labor to begin producing and drawing exporting fixed costs in the next period. Firms in country $i$ enter when the fixed cost is less than the expected discounted value of profits. The free entry condition is

where

$$
W_{i} f_{e}=n_{s} \mathbb{E} D_{i}\left[V_{d o m, i}^{\prime}+\sum_{j \in I} V_{0, i j}\right]
$$

$$
V_{d o m, i}=\pi_{N T i i}+n_{s} \mathbb{E} D_{i}^{\prime} V_{d o m, i}^{\prime}
$$

and

$$
V_{0, i j}=-W \int_{0}^{\kappa^{*}} \kappa d F_{0}(\kappa)+n_{s} \mathbb{E} D\left[V_{0, i j}\left(\kappa^{\prime}\right)+F_{0, i j}\left(\kappa_{i j}^{*}\right)\left[V_{1, i j}\left(\kappa^{\prime}\right)-V_{0, i j}\left(\kappa^{\prime}\right)\right]\right] .
$$

The mass of entrants in country $i$ is denoted $N_{e i}$. 


\subsection{Aggregation and Market Clearing}

Because the fixed cost distributions are iid across firms and time and only depend on export status, it's easy to integrate over individual choices of firms to get aggregate variables. Instead of tracking fixed cost distributions across firms, we only need to keep track of the number of exporters in each market.

There are $N_{i, t}=n_{s}\left(N_{i, t-1}+N_{e i, t-1}\right)$ intermediate goods producers in region $i$ at time $t$. The exporting decision relies only on export history and the threshold fixed cost, so the number of exporters in market $j$ at time $t$ is

$$
N_{i j, t}=n_{s} N_{i j, t-1} F_{1 i}\left(\kappa_{i j, t-1}^{*}\right)+n_{s}\left(N_{i, t}-N_{i j, t-1}\right) F_{0 i}\left(\kappa_{i j, t-1}^{*}\right) .
$$

Now we can aggregate across individual firm prices to get the price for bundles

$$
P_{N T i i}=\hat{N}_{i}^{\frac{1}{1-\theta}} \frac{\theta}{\theta-1} M C_{i} \quad P_{G i j}=\left(\frac{N_{i j}}{N_{i}}\right)^{\frac{1}{1-\theta}} \xi_{G i j} P_{N T i i} .
$$

The price of a bundle of goods in a market is decreasing in the number of suppliers to the market, reflecting the love of variety that consumers have in the model.

Because production is CES and inputs are adjustable, firm demand for inputs can be solved separately for each market. The average capital used by a region $i$ firm selling to region $j$ is

$$
k_{i j}=\psi_{i} \hat{N}_{i j}^{\frac{\theta}{1-\theta}} \sum_{G} \xi_{G i j} \hat{G}_{i j}
$$

where $\psi_{i}=M C_{i} \frac{\alpha\left(1-\alpha_{m}\right)}{R_{i}}$. Capital used to produce goods for region $i k_{i i}$ includes capital used for the domestic market and the capital used by the $N_{i i}$ firms that export to other countries in region $i$. Total capital demanded as inputs for production is

$$
K_{i}^{d}=N_{i} k_{i i}+\sum_{j \neq i} N_{i j} k_{i j}
$$

and the market clearing condition for capital is $K_{i}^{d}=K_{i}$ supplied by households.

Using the solution from the intermediate producers' problem, the total demand for labor and materials used in intermediate good production $L_{p}$ and $M$ is

$$
L_{p i}=\frac{1-\alpha}{\alpha} \frac{R_{i} K_{i}}{W_{i}} \quad \text { and } \quad M_{i}^{d}=\frac{\alpha_{m}}{\left(1-\alpha_{m}\right) \alpha} \frac{R_{i} K_{i}}{P_{M i}} .
$$

The market clearing condition for materials is that $M_{i}^{d}=M_{i}$ supplied by final goods 
producers. The market clearing condition for total labor is that labor supplied by households $L_{i}$ is equal to the sum of intermediate good production labor $L_{p}$, final good production labor $\Sigma_{G} L_{G}$, and labor used to pay fixed costs $F C_{i} / W_{i}$. Total fixed costs paid in region $i$ in period $t$ are

$$
F C_{i}=W_{i}\left[N_{e i} f_{e i}+\sum_{j \in I} N_{i j} \int_{0}^{\kappa_{i j}^{*}} \kappa d F_{1 i j}(\kappa)+\left(N_{i}-N_{i j}\right) \int_{0}^{\kappa_{i j}^{*}} \kappa d F_{0 i j}(\kappa)\right] .
$$

Aggregate profits earned by a firm in $i$ selling to market $j$ are

$$
\pi_{i j}=\frac{\sum_{G} P_{G i j} G_{i j}}{\theta N_{i j}}
$$

and total profits transferred to households are

$$
\Pi_{i}=N_{i} \pi_{i i}+\sum_{j \neq i} N_{i j} \pi_{i j}-F C_{i} .
$$

Finally, risk-free bonds are in zero net supply $\sum_{i} B_{i}=0$.

An equilibrium is a set of prices and quantities for all commodities that solve the consumers problem, the final goods producers problem, and the intermediate goods producers problem and that satisfy all market clearing conditions.

\section{Calibration}

The calibration prioritizes reproducing the features of the micro data that were illustrated in Section 2: that export churning is low on average, and that churning is higher for minor export destinations.

The values for all parameters are shown in Table 2. The discount factor $\beta=0.96$, the capital depreciation rate $\delta=0.1$, and the intertemporal elasticity of substitution $1 / \sigma=1$ all take standard values from the literature. Lacking consistent estimates on the elasticity of substitution between home and foreign goods $\gamma$, I set it equal to 4, which implies a short-run (one-year) trade elasticity of about 3 in the model. I set $\theta=6$ to get a markup of 20 percent. The survival rate $n_{s}=.98$ implies that 2 percent of firms die each year. The rate is set to match the share of labor in exiting firms rather than the actual fraction of firms that exit as explained in Alessandria and Choi (2014).

Cobb-Douglas parameters $\alpha_{m}$ and $\alpha_{G}$ for $G \in\{C, X, M\}$ determine the ratio of gross 
output to value added in intermediate goods and in each final good. Because the world will be split into multi-country regions, these ratios are difficult to obtain at the region level. Instead, I assume that the parameters are the same for all regions and use U.S. data to calibrate the values. BEA GDP data by industry can be used to separately calculate ratios of gross output to value added in investment, materials, and consumption. The implied ratio for investment and materials together is about 2.2. For consumption, the value is about 1.65. Gross output to value added in the intermediates sector can be written as $1 /\left(1-\alpha_{m} \frac{\theta-1}{\theta}\right)$. Assuming the final good production of investment and material goods requires no domestic labor $\left(\alpha_{X}=\alpha_{M}=1\right)$ implies $\alpha_{m}=0.65$. The share of labor in final consumption production $\alpha_{C}$ is then set to be 0.72 to match the ratio of gross output to value added for consumption in the United States.

While the model is tractable, it still has $I^{2}+3 I$ state variables. To keep the state space manageable, I split the world into multi-country regions. I model China and the United States explicitly, as they are the two largest economies and represent a large share of global trade. Their major trade partners are represented by three regions: a rest of NAFTA aggregate that includes Mexico and Canada (NAFTA), an East Asian aggregate $(\mathrm{EA})^{3}$, and the European Union $(\mathrm{EU})$. The rest of the world is grouped into a sixth region (RoW). It is assumed that multi-country regions (all but the U.S. and China) contain two identical countries that can also trade with each other subject to fixed and variable costs. This assumption allows the model to match each region's total reliance on trade, which is important for borrowing and lending responses after trade liberalizations.

Labor endowments are chosen to match the relative population size of each region where the U.S. is normalized to have $\bar{L}=1$. The U.S. is also normalized to have productivity $z=1$. The productivity of other regions will be determined internally.

The parameters that remain to be calibrated include the relative preference for consumption and leisure $\mu$; the share of labor in value added $1-\alpha$; the entry cost $f_{e}$; initial tariffs $\tau_{j i}$; parameters in the distributions of fixed costs $f_{0, i}, f_{1, i}$, and $v$; country-specific technology $z_{i}$; and good-specific iceberg costs $\left\{\xi_{G i j}\right\}_{G \in\{C, X, M\}}$. These parameters, except for $v$ and $\tau_{j i}$, are

\footnotetext{
${ }^{3}$ The East Asia aggregate includes Japan, South Korea, Hong Kong, Vietnam, Thailand, Malaysia, Singapore, Indonesia, and the Philippines.
} 
chosen jointly to match specific moments in the data. The target moments described later below can be matched for any arbitrary $v$ in $(0,1)$ and for any tariffs $\tau_{j i}$. Later on, $v$ (and its accompanying calibration for other parameters) will be chosen to capture the positive relationship between export persistence and export volume. Initial tariffs will vary based on the quantitative experiment that is explored.

Of the parameters that remain, $\mu, \alpha$, and $f_{e}$ are not region-specific. I start by calibrating a symmetric two-country version of the model to match the following moments with arbitrary $v$ :

1. Frisch elasticity of 2

2. labor share of value added equal to $66 \%$

3. number of firms normalized to 1

4. export-weighted average incumbent export share $=97 \%$

5. fraction of firms that export $=45 \%$

6. $z_{1}=z_{2}=1$

7. imports to GDP ratio $=22.3 \%$

8. investment goods share of imports $=18.4 \%$

9. material goods share of imports $=59.3 \%$.

The fourth moment comes from a similar data exercise as in Section 2 where the incumbent shares for Mexican exporters are for the six regions specified earlier. I match the incumbent export share rather than the incumbent exporter share. Because exporters in the model are homogeneous in their sales, matching the incumbent exporter share would exaggerate the contribution of new exporters to total exports. This point is explored more fully in Alessandria et al. (2018), who build a model that captures the growth of new exporters in foreign markets over time. Such a model would be difficult in the current setting, but the exercises in their paper reveal that a model with high sunk costs matching higher incumbent 
shares as in this model yields dynamics and welfare gains similar to those in the model that explicitly accounts for exporter growth.

The fifth moment, which summarizes export participation, is representative of export participation in countries that have such data. I am not aware of any datasets that report export participation for more than a few countries. The last three moments are averages across the regions and countries that will be in the full model.

The symmetric calibration gives values for $\mu, \alpha$, and $f_{e}$ that are consistent with a dynamic exporting model. The same values are used in the six-region asymmetric calibration, which replaces moments 6 through 9 above with

6a. each region's 2014 GDP relative to the U.S.

7a. bilateral imports over GDP for each region pair (and countries within a region)

8a. bilateral investment goods share of imports

9a. bilateral material goods share of imports.

Lacking region-specific data on incumbent shares or export participation, we continue to assume that they are the same for all countries. To clarify, incumbent shares and the number of exporters can be different for each destination, but the average incumbent share and the total number of exporters are the same as in the symmetric model.

The asymmetric calibration accounts for the heterogeneous trade compositions that each country has with its trade partners, which is an important component of evaluating trade policy $\rfloor^{4}$ For example, in 2014, 36 percent of U.S. imports from China and 4 percent of U.S. imports from the RoW region were capital goods. So we would expect that a trade agreement between the U.S. and China that takes all tariffs to zero will therefore have a much larger impact on U.S. investment than would a similar trade agreement between the U.S. and the RoW as it represents a larger drop in the price of U.S. investment $5^{5}$

\footnotetext{
${ }^{4}$ The breakdown of trade into different goods uses BEC end-use classifications from COMTRADE. The exact breakdown is described in Appendix D

${ }^{5}$ Matching actual trade flows, including trade imbalances, in 2014 implies net foreign asset positions that are sometimes contrary to the data. Many researchers adjust initial trade flows so that they are balanced in the initial steady state and imply zero net foreign assets for all countries. But in this model, I find that the initial trade flows and composition are more important for aggregate dynamics than the effects of nonzero initial net foreign assets so I keep the trade flows from the data.
} 
The calibration of the model matches all targeted moments exactly for arbitary $v$ in $(0,1)$.

\section{Model Fit - Churning and the export response}

Though the relationship between export churning and export volume was not explicitly targeted, we can capture the relationship with our choice of $v$, the shape parameter in the fixed cost distributions. Figure 2 shows bilateral incumbent shares relative to total export volume. The first panel is data on Mexican incumbent export shares for the six regions in the model. The second panel shows bilateral incumbent shares in a calibration where $v$ is close to zero for all region pairs in the model. The third panel shows the same incumbent shares in the model from a calibration with $v=1$. With a lower $v$, the model captures the strong relationship between incumbent shares and export volumes and gives a range of incumbent shares similar to the Mexican data. With a higher $v$, churning looks more uniform across trade partners.

The intuition for this result is shown in Figure 3. Each panel shows the exporter and nonexporter distributions for European exporters and the threshold fixed costs for a destination with high exports, the U.S., and a destination with low exports, NAFTA, in steady state. Higher exports translate to higher threshold fixed costs in the model; firms gain higher profits and are willing to pay more to export to major export destinations. The left panel in the figure shows the distributions for $v$ close to zero and the right panel shows the same for $v=1$. Because firms are homogeneous in productivity, the incumbent export share is just the share of exporters that are incumbents. In steady state, we can express this share as $n_{s} F_{1}\left(\kappa_{i j}^{*}\right)$, the probability of survival times the probability of continuing to export to $j$.

When $v$ is near zero, incumbent exporters to the U.S. and NAFTA have a 97.1 and 89.0 percent probability, respectively, of continuing to export. When $v=1$, fixed cost draws are concentrated at low values, and the distribution is roughly flat between the two thresholds so that the probability of continuing is similar for incumbents to either destination: 98.2 percent for exporters to the U.S. and 96.2 percent for exporters to NAFTA. Higher values of $v$ result in even more uniform churning across destinations. 
Because the calibration with $v$ close to zero $(v=0.0001)$ captures the relationship between persistence and exports, I use that calibration for all results to follow. Note that regardless of the shape of the distribution, export churning is an endogenous outcome of individual firms' exporting decisions. Firms optimally choose the threshold fixed cost that determines their export status; the shape of the distribution determines how many firms are at the margin.

\subsection{Exporter Churning and Aggregate Export Dynamics}

Variation in export churning determines the heterogeneity in aggregate export responses across destinations through the extensive margin. The extensive margin of trade adjusts faster in destinations with more churning, generating faster growth in bilateral exports.

Consider a model that, for exposition, abstracts from labor inputs in final goods, multiple countries within regions, and good-specific iceberg costs. The bilateral equation for exports is

$$
E X_{i j t}=P_{i j t} G_{i j t}=\tau_{i j t}^{-\gamma}\left(\frac{N_{i j t}^{\frac{1}{1-\theta}} \xi_{i j t} \frac{\theta}{\theta-1} M C_{i t}}{P_{j t}}\right)^{1-\gamma} Y_{j t}
$$

where $Y_{j t}=P_{j t} G_{j t}$ is region $j$ 's total expenditure on intermediates.

Changes in country $i$ 's marginal cost $M C_{i t}$ affect its exports to all destinations in the same way. Similarly, destination $j$ 's price $P_{j t}$ and expenditure $Y_{j t}$ affect imports from all sources in the same way. I assume that iceberg costs take the form $\ln \xi_{i j t}=\ln \bar{\xi}_{i j}+\ln \tilde{\xi}_{i j t}$. The fixed component $\bar{\xi}_{i j}$ measures iceberg costs between countries $i$ and $j$ that do not change

over time such as distance while $\tilde{\xi}_{i j t}$ changes over time because of nontariff trade policy, advancements in shipping technology, etc. We can rewrite the export equation in logs as:

(2) $\ln E X_{i j t}=-\gamma \ln \tau_{i j t}+(1-\gamma) \ln \tilde{\xi}_{i j t}+\frac{1-\gamma}{1-\theta} \ln N_{i j t}+\alpha_{i t}+\alpha_{j t}+\alpha_{i j}$

where the $\alpha$ terms contain source-specific, destination-specific, and pair-specific variables discussed above.

Now suppose a trade liberalization between countries $i$ and $j$ lowers the tariff $\tau_{i j t}$ permanently (lowering iceberg costs has a similar intuition). On impact, the number of exporters is fixed and changes in exports are driven by the intensive margin response $-\gamma \Delta \ln \tau_{i j 0}$ and 
general equilibrium factors (the $\alpha$ terms). This effect is roughly the same for all destinations except for some variation in general equilibrium factors.

The dynamics of the export response over time are driven by changes in the number of exporters $N_{i j t}$. Because a liberalization makes exporting more profitable, more firms become exporters and more incumbent exporters continue exporting. The growth in the extensive margin leads to higher exports so the long-run trade elasticity is larger than the short-run trade elasticity, consistent with data on export behavior after free trade agreements. The speed of adjustment depends on destination-specific export churning. Looking again at the left panel of Figure 3, imagine a liberalization with the U.S. and NAFTA as a shift to the right in the export thresholds. More nonexporters will enter and more exporters will continue to export in both markets. But the probability of continuing to export increases by more in NAFTA for an equivalent change in the threshold because there are more incumbent exporters that draw fixed costs just above the initial threshold and therefore benefit from the policy. Furthermore, entrants make up a larger share of total exports to NAFTA and more of these entrants will become incumbents than in steady state. The result is that the extensive margin adjustment is faster and larger in NAFTA than in the U.S.

Figure 4 shows the U.S. export response to all five regions after a global liberalization that brings all bilateral tariffs from 5 percent to 0 . The solution assumes that after the initial shock, agents have perfect foresight over the future of policy. The change in bilateral exports to NAFTA, to which the U.S. exports most, is clearly both slowest and smallest while the change in bilateral exports to China, to which the U.S. exports least, is the fastest and largest. Exports to the other destinations are less clearly differentiated.

To see the relationship between initial export volume and export growth in the model more generally, I use the simulated data to estimate the effect of initial export volumes on the 10-year change in log exports with a liberalization at $t=1$ :

$$
\ln E X_{i j, 10}-\ln E X_{i j, 0}=\beta \ln E X_{i j, 0}+\alpha_{i}+\alpha_{j}+\varepsilon_{i j} .
$$

The results of the estimation are reported in the first row of Table 3 . A 10 log point increase in initial exports results on average in a $0.45 \log$ point decrease in the 10-year export change. To put that in perspective, the coefficient predicts that after 10 years, the growth in U.S. 
exports to China will be 35.1 percent while growth in U.S. exports to NAFTA will be only 30.4 percent. The coefficient is highly significant.

Consider another estimation that uncovers the effect of initial exports on the long run growth in bilateral exports. I estimate

$$
\ln E X_{i j, L R}-\ln E X_{i j, 0}=\hat{\beta} \ln E X_{i j, 0}+\hat{\alpha}_{i}+\hat{\alpha}_{j}+\hat{\varepsilon}_{i j} .
$$

The coefficient $\hat{\beta}$ is once again highly significant and negative, implying that exports to smaller export partners grow by much more in the long run.

Table 3 also reports estimates for each coefficient in models with uniform churning $(v=$ 4), no extensive margin (all firms export to all destinations $f_{1 i}=f_{0 i}=0$ ) and a model with a static exporting decision $\left(f_{1 i}=f_{0 i}\right)$. The second two cases are most common in multicountry studies. With uniform churning, the coefficients for initial and long run growth are still negative and significant but are much smaller than predicted in the benchmark model because heterogeneous churning drives the differences across countries. A $10 \log$ point increase in initial exports increases the growth in exports over the first 10 years of the agreement by only $0.01 \log$ points and the growth in log run exports by only $0.4 \log$ points.

With no extensive margin of trade in the export equation (when all firms export), the export response is almost identical for all destinations, and estimations for each coefficient are insignificant. The static exporting model generates only slightly higher growth for minor export partners, similar to the model with uniform churning.

To summarize, the benchmark model predicts that exports to minor export partners grow faster in the short run and have higher long run growth than exports to major destinations after a liberalization. These predictions are unique to the benchmark model with dynamic exporting and destination-specific churning. The next section reviews empirical evidence regarding these predictions.

\subsection{Export responses in the data}

We want to see if the predictions of the model regarding export responses for major and minor export partners hold true in the data. Unfortunately, trade costs are not directly observed in the data. Liberalizations in trade generally involve changes in both tariff and 
nontariff barriers. While tariffs can be observed, studies have shown they account for a small fraction of total trade costs (see Anderson and Van Wincoop (2003)).

To get around this problem, I use the existence of a free trade agreement between two countries as an indicator for the level of trade costs as in Baier and Bergstrand (2007). The estimating equation in Baier and Bergstrand's paper is

$$
\ln E X_{i j t}=\sum_{k=0}^{2} \beta_{k} F T A_{i j, t-k}+\alpha_{i t}+\alpha_{j t}+\alpha_{i j}+\varepsilon_{i j t} .
$$

where $F T A_{i j t}=1$ if countries $i$ and $j$ have a free trade agreement at time $t, \alpha_{i t}$ is a sourcetime fixed effect, $\alpha_{j t}$ is a destination-time fixed effect, and $\alpha_{i j}$ is a source-destination fixed effect. A time period in the regression is five years. The lagged values of the free trade agreement indicator are meant to capture dynamic changes in exports after a liberalization. The model suggests gradual growth in exports are due to increases in the extensive margin.

I use a dataset similar to Baier and Bergstrand with annual bilateral exports between most countries in five-year periods between 1960 and 2005 6 Two countries $i$ and $j$ have a free trade agreement at time $t$ if one has been reported to the WTO by or before time $t$. I remove any pairs of countries with zero or nonreported trade in any two of the ten periods from 1960 to 2005. Performing the same regression as in Baier and Bergstrand yields similar results as their paper: a free trade agreement more than doubles bilateral trade, and the increase occurs gradually over the 10 to 15 years after the liberalization. The impulse responses are shown in Table 4 .

But how do the export responses differ across trading partners? Define a major export partner in time $t$ as a destination that is in the top quartile of a country's export destinations in that year. I estimate

$$
\ln E X_{i j t}=\sum_{k=0}^{2} \beta_{k} F T A_{i j, t-k}+\gamma_{k} \text { Major }_{i j, t-k}+\delta_{k} F T A_{i j, t-k} \times \text { Major }_{i j, t-k}+\alpha_{i t}+\alpha_{j t}+\alpha_{i j}+\varepsilon_{i j t}
$$
where Major $_{i j t}=1$ if country $j$ is a major export partner for country $i$ at time $t$. The coefficients $\delta_{k}$ yield the differential effects of having a free trade agreement at time $t-k$ if

\footnotetext{
${ }^{6}$ Bilateral export data is from the IMF Direction of Trade Statistics. Free trade agreement data is from the CEPII gravity database. The qualitative results presented here about the difference in export responses for major and minor trade partners are robust to inclusion of later data in 2010 and 2015. However, the trade collapse during the global financial crisis causes the estimation to yield strange point estimates so results are shown for data ending in 2005.
} 
the agreement partner was a major export partner when the agreement began. An implicit assumption is that the magnitude of trade cost changes and the shape of tariff phaseouts do not differ significantly across major and minor export partners.

Table 4 reports the impulse responses for a new free trade agreement between two countries. In the first zero to four years, exports to minor export partners with whom a free trade agreement has been implemented increase by 41 percent $\left(e^{\beta_{0}}\right)$. By contrast, exports to major export partners only grow by 8 percent $\left(e^{\beta_{0}+\delta_{0}}\right)$. In the next five years, the gap widens even more. After five to nine years, exports to minor partners have grown a total of 92 percent and exports to major partners by only 28 percent. Wald tests with a null hypothesis equal export responses after zero to four years or five to nine years are both strongly rejected with p-values less than 0.001.

The long-run growth in bilateral exports after a free trade agreement is also larger for minor export partners. On average, long-run bilateral exports to a minor export partner increase by 128 percent while exports to a major export partner only increase by 60 percent. A Wald test with a null hypothesis $L A T E_{\text {Major }} \geq L A T E_{\text {Minor }}$ yields a p-value of 0.002.7

Let's take stock of how the predictions of the model pan out in the data. First, the model predicts exports to minor export partners grow much faster than exports to major export partners after a trade liberalization. This prediction is true in the data. In the first five to nine years, the difference in growth for the two export partner categories was quantitatively large (92 percent vs 28 percent) and statistically significant at the $0.1 \%$ level. Second, the model predicts that the long-run export response is higher for minor export partners than for major partners, which is also validated in the data.

The results are robust to several variations of the estimation. I drop destinations with low average exports over time. For example, when Canada signs an agreement with the EU, it gains better access to Cyprus's market, with which it trades very little, and even a small increase in exports results in huge growth. Dropping export partners with low average exports alleviates this issue. I also consider various thresholds for what constitutes a major

\footnotetext{
${ }^{7}$ The impulse responses from the original Baier-Bergstrand specification do not lie in the middle of the impulse responses for major and minor export partners as one might expect. Recall that the new estimating equation includes both an interaction term and the major export partner term alone. It is the major export partner variable that lowers the impulse response relative to Baier-Bergstrand.
} 
export partner for a country. The qualitative results presented above are robust to these variations.

Again, the export responses that have been shown to qualitatively match the data are unique to the model with a dynamic exporting decision and heterogeneity in exporter churning across destinations. Existing multi-country models with no dynamic adjustment margin in the export equation predicts that export growth is instantaneous and roughly identical across all destinations. Thus, the benchmark model better matches the behavior of bilateral exports after changes in trade policy, as expected.

\section{Global Liberalization - Welfare and Dynamics}

My multi-country model that matches variation in export churning across destinations has important implications for aggregate welfare and dynamics because of its ability to explain export behavior both over time and across destinations. This section explores the aggregate effects of a global liberalization from current tariffs as predicted in the model.

First, initial levels of tariffs between regions and countries in the model must be changed to match current data $\sqrt[8]{ }$ World Bank data on weighted average tariff rates is available for most countries $!^{9}$ The region-level tariffs on incoming goods $\tau_{i}-1$ are calculated as GDPweighted measures of country-specific tariffs. But a region does not impose the same tariff on all countries. Some regions have free trade agreements that have already reduced tariffs to zero. To account for these agreements, I set tariffs between the US and NAFTA, within NAFTA, within the EU, and within EA to zero (i.e. $\tau_{j i}=1$ if $i$ and $j$ have a free trade agreement). Tariffs on all other countries $\bar{\tau}_{i}-1$ are set equally for destination region $i$ so that the total import value inclusive of tariffs is consistent with the weighted average tariff from the data $\tau_{i}$ :

$$
\bar{\tau}_{i} \sum_{N o F T A} I M_{i j}+\sum_{F T A} I M_{i j}=\tau_{i} \sum I M_{i j}
$$

where $I M_{i j}$ is region $i$ imports from region $j$. The tariff $\bar{\tau}_{i}$ is similar to a most-favored-nation

\footnotetext{
${ }^{8}$ I use data from 2014 which predates the recent rise in trade tensions.

${ }^{9}$ Using the import-weighted average of tariffs introduces downward bias in the tariff measure as goods with high tariffs are traded less. Also, the measure of barriers excludes non-tariff barriers which can be quite high. Thus, the size of the liberalization in the experiment should be interpreted as a lower bound.
} 
tariff in the WTO. It is the default tariff charged on any trade partner with which there is no free trade agreement. The tariff values $\bar{\tau}_{i}$ are reported in Table 5 .

\subsection{Welfare gains}

Suppose a global liberalization permanently reduces all tariffs to zero. Welfare gains $\eta$ are the percent change in initial steady state consumption that make a region indifferent between staying at the steady state forever and having the global liberalization. That is, for country $i, \eta_{i}$ solves

$$
\frac{u\left(\left(1+\frac{\eta_{i}}{100}\right) C_{i}^{*}, \bar{L}_{i}-L_{i}^{*}\right)}{1-\beta}=\sum_{t=0}^{\infty} \beta^{t} u\left(C_{i t}, \bar{L}_{i}-L_{i t}\right)
$$

where $x^{*}$ denotes the initial steady state value of $x$ and the global liberalization occurs at time $t=0$. The welfare gains for each country are reported in Table 6 .

The U.S. and NAFTA gain the least from a free trade agreement, about 0.5 and 0.6 percent. China, East Asian countries, and the RoW region gain the most from a liberalization with gains between 1.9 and 2 percent. Europe lies in the middle with gains of about 1 percent. What accounts for the differences? First, the U.S. depends less on trade than the other regions so moving to free trade has a smaller impact on the aggregate economy. East Asia, however, depends a lot on trade, and the benefit of zero tariffs is large. Second, welfare gains are sensitive to initial tariffs. Canada and Mexico, though highly dependent on trade, trade mostly with the U.S., where tariffs are already at zero. The decrease in tariffs in other parts of the world has a smaller effect. The U.S. and NAFTA also have lower tariffs on goods in general than other countries.

The openness and initial tariffs of a country can be summarized in the sales effective tariff $\tau_{S E i}$ and expenditure effective tariff $\tau_{E E i}$, defined as the weighted average of tariffs on all sales or expenditures in the initial steady state of the model:

$$
\tau_{\text {SE } i}=\frac{\sum_{j}\left(\tau_{i j}-1\right) \text { Sales }_{i j}}{\sum_{j} \text { Sales }_{i j}+\text { Sales }_{N T i i}} \quad \tau_{E E i}=\frac{\sum_{j}\left(\tau_{j i}-1\right) \text { Sales }_{j i}}{\sum_{j} \text { Sales }_{j i}+\text { Sales }_{N T i i}} .
$$

The effective tariffs are reported in Table 5. The average tariff applied to a good sold by a U.S. intermediate goods producer is 0.18 percent and the average tariff charged on a good bought by a U.S. final goods producer is 0.14 percent. By contrast, the average tariff on 
Chinese sales is 0.51 percent and the average tariff on a good bought by China is 0.69 percent. China gains more from a global liberalization because its exporters become much more competitive in foreign markets and imported goods become much cheaper.

The relative gains of each country determine their borrowing and lending decisions. After the liberalization, countries would like to buy more goods in the short run to consume more and build capital stocks. At the steady state world interest rate, all countries would want to borrow. The interest rate rises until regions like the U.S. and NAFTA that gain less from the liberalization are better off lending. Thus, the regions with larger gains from the agreement borrow from countries with smaller gains. These dynamics are shown in the changes in steady state net foreign asset holdings $b_{i}$ as a share of initial steady state GDP, reported in Table 6. The U.S. increases net foreign assets by 6.2 percent of GDP, NAFTA by 6.4 percent, and Europe by 6.2 percent. China reduces net foreign assets by 9.5 percent of GDP, East Asia by 2.2 percent, and the RoW by 5.8 percent.

\subsection{Aggregate dynamics after the liberalization}

Appendix E derives a simple decomposition of changes in domestic absorption over time:

$$
\begin{aligned}
\breve{D A \approx} \frac{\alpha_{C}}{1-\gamma} & \left(\breve{\lambda}_{C}+\frac{\alpha_{m}}{1-\alpha_{m}} \breve{\lambda}_{M}\right)+\alpha \alpha_{C}\left(\breve{K}-\breve{L}_{p}\right)+\frac{\alpha_{C}}{\left(1-\alpha_{m}\right)(\theta-1)} \breve{N}+\breve{L}_{p} \\
& -\sum_{G} \frac{\tilde{s}_{G}}{1-\tilde{s}_{M}}\left(\breve{A}_{G}-\breve{S}_{G}\right)
\end{aligned}
$$

where $\breve{x}$ is the log change of variable $x$ from the initial steady state;

$$
\breve{D A}=\left[\tilde{s}_{C} \breve{C}+\tilde{s}_{I}\left(\breve{P}_{I}-\breve{P}_{C}+\breve{I}\right)\right] /\left(1-\tilde{s}_{M}\right)
$$

is a weighted measure of domestic absorption; $\lambda_{G}$ is the good $G$ specific domestic expenditure share; $L_{p}$ is labor employed in production of intermediate goods; $N$ is the number of domestic firms; $A_{G}$ is the ratio of intermediate goods producers revenue for $G$-destined goods to tariff-exclusive expenditure on intermediate goods destined for $G$ and thus covaries with the good-specific trade balance; $S_{G}$ is an expenditure-weighted average of tariffs on good

$G$; and $\tilde{s}_{G}$ is the steady state value of $\frac{\alpha_{G} \tilde{P}_{G} \tilde{G} A_{G} / S_{G}}{\sum_{H} \alpha_{H} \tilde{P}_{H} \tilde{H} A_{H} / S_{H}}$, which is the share of final goods producers' expenditure on intermediates of type $G$ weighted by their importance in final good production and trade. 
The decomposition breaks movements in weighted domestic absorption into changes in trade (the $\lambda$ terms), capital deepening, number of firms, production labor, good-specific trade imbalances, and tariff revenue. Figure 5 shows each of these contributions over the first 40 years after the global liberalization for China, the region that gains most from the policy change. Note that the lines show contributions of, say, the number of firms to domestic absorption, not the actual change in the number of firms. The figure also shows the transions in consumption and investment separately. The following paragraphs discuss the dynamics of each component.

Trade $(\lambda)$. The liberalization makes imported goods cheaper, and China shifts its expenditure towards imported goods as seen in the trade term. Over time, more foreign exporters enter the Chinese market, further driving down the cost of imports so that China's expenditures shift even more towards imports. The long-run contribution of changes in $\lambda$ is more than double the short run.

Firms $(N)$. Chinese exporters benefit from unrestricted access to foreign markets. But potential entrants in China still view exporting as a rare opportunity and discount those benefits in the value of entry. However, new exporters from other countries entering the Chinese market drive down the profits of operating domestically. As a result, fewer firms enter. The resulting fall in the number of firms diminishes domestic productive capacity and takes away from consumption and investment in the long run.

The substitution between firms and exporters is a key component of all trade models with a dynamic exporting decision and endogenous firm entry. It drives the overshooting behavior that we see in consumption and investment. In the initial years after the liberalization, potential entrants stop paying the expensive fixed cost to enter the domestic market, freeing up resources for use in consumption and investment. But the lack of entrants in the short run reduces domestic productive capacity in the long run, reducing the long-run level of consumption and investment.

This model delivers less overshooting than two-country models such as Alessandria et al. (2018) because of the endogenous labor decision and capital-intensive trade. My model without these features would predict the same strong overshooting.

Production labor $\left(L_{p}\right)$. Because tariffs are a tax on consumption, removing tariffs 
causes consumers to shift away from leisure and toward consumption so labor increases. Also, less fixed cost labor is required in the short run because of the lack of entering firms. As a result, labor in production of intermediates increases by more in the short run.

Capital deepening $\left(K / L_{p}\right)$. The liberalization increases the wages of workers and decreases the cost of goods so growth in capital outpaces production labor. Because trade is intensive in capital goods, the decrease in tariffs has a larger impact on the price of investment than other goods prices, which further strengthens the incentive to invest.

Trade imbalances $\left(A_{G}\right)$ China also benefits from its ability to borrow against future income, as shown by the contribution of good-specific trade imbalances $\Sigma_{G} A_{G}$. The initial increase is consistent with the borrowing patterns mentioned previously. China borrows in the short run to fund larger increases in consumption and investment. Eventually, China must pay back interest on the loans 10

Tariff revenues $\left(S_{G}\right)$. Finally, eliminating tariffs also eliminates tariff revenue which shows up as a static drag on consumption and investment.

\subsection{Destination-specific churning - a key driver of aggregate re- sults}

How does destination-specific churning affect the short run and long run response to the global liberalization? To answer this question, consider an alternative calibration of the model with $v=4$ so that churning is roughly uniform across trading partners.

Table 6 and Figure 5 show the welfare gains and China's dynamic response in the model with uniform churning. Welfare gains are lower for all regions than in the benchmark model. China's welfare gains, for example, drop from 2 percent to 1.6 percent.

The contribution of trade dynamics to domestic absorption in Figure 5 shows the disparity between the two models. The lower aggregate response of China's import contribution is because of smaller bilateral import responses. For example, China is a minor export destination for the U.S. In the benchmark model, U.S. exports to China exhibit high churning

\footnotetext{
${ }^{10}$ The dynamics of $\Sigma A_{G}$ reflect the sum of dynamics in good-specific trade imbalances. The level is sensitive to reallocation of trade imbalances among various goods and initial net foreign assets. This sensitivity is the reason that the long run contribution of $\Sigma A_{G}$ is positive for China, even though China is paying back debt.
} 
and growth in exports is fast and large. But when churning is uniform and high to match export-weighted average churning across destinations, growth in exports from the U.S. to China is slower and smaller, and this pattern holds for all source-regions for which China is a minor export partner. For the other regions, say East Asia, there may be slightly more churning in the uniform churning model, but not enough to offset the smaller export responses from other regions.

The smaller aggregate trade contribution to absorption also results in less capital deepening. When fewer exporters enter the Chinese market, the price of investment falls by less and Chinese consumers invest less than in the benchmark model. But the lower contribution of capital is offset by a less negative contribution of firm exit. Because there are fewer foreign exporters in China, domestic firms face less competition and entry decreases by less than in the benchmark model.

The model with uniform churning results in lower Chinese consumption in both the short and long run. The short-run difference in consumption is due to consumer expectations about future welfare gains. Consumers in the benchmark model expect higher gains, so they consume more today. Investment is higher in the short run but lower in the long run with uniform churning. In the benchmark model, consumers wait for the foreign exporters to enter and further drive down the price of capital goods before investing. When fewer foreign exporters are expected to enter, the incentive to delay investment diminishes. Overall, accounting for variation in churning across trade partners is a key driver for aggregate welfare and dynamics.

\subsection{Comparison to a static exporter model}

Like the benchmark model, a static exporter model features an extensive margin of trade as a component of aggregate trade flows. The difference is that firms make the decision to export based only upon the exporting profits that would be gained in the current period; the export decision is not forward-looking. As we saw in Section 5, the static exporter model is unable to explain the heterogeneous export response across destinations. But how different are the aggregate consequences of a liberalization in a static exporter model?

I change the timing of the benchmark model so that firms can enter and start producing 
for both the domestic and foreign markets in the same period that they pay the fixed cost. In a static model, the fixed cost distribution is the same for nonexporters and exporters $f_{1}=f_{0}$, so the model cannot match the low export churning in the data. I keep the shape parameter of the fixed cost distribution $v$ the same so that there is significant variation in the entry probability for each destination (the static analog to destination-specific churning). All other target moments for calibration are the same ${ }^{11}$

The welfare gains from the static exporter and benchmark model are nearly identical (see Table 6). But the sources and timing of the welfare gains in the two models are different, which we can see in the decomposition of absorption over time in Figure 5.

In the static model, the extensive margin of trade (and therefore trade) adjusts immediately to its optimal level. China uses the fast adjustment in trade to borrow even more in the inital years after the agreement, as shown by the contribution of $\sum_{G} A_{G}$ and the overshooting in the trade contribution. They also export more to foreign countries and require more production labor. The large increases in trade, borrowing, and labor allow China to invest and consume more in the initial periods compared to the benchmark model.

The increase in trade does not dissuade entering firms as much as it did in the benchmark model. Because the possibility of becoming an exporter at some point is much higher than in the benchmark model, firms do not discount the increase in export profits by as much in the static model. In the long run, China has more firms in the static model. But the increased capacity at home comes at a price. Foreign firms that would export to China in the benchmark model now face more competition from domestic firms and decide not to enter. The long run contribution of trade and capital deepening is therefore higher in the benchmark model.

In summary, while the overall gains from a global trade liberalization are similar in the static and benchmark models, the sources and timing of those gains are different. Gains in the static model come from the fast adjustment in trade and higher long run domestic productive capacity while gains in the benchmark model come from higher long run trade

\footnotetext{
${ }^{11}$ I maintain the elasticity of substitution $\gamma$ from the initial calibration. As a result, the average trade elasticity in the static model is smaller. Some researchers increase $\gamma$ in the static model so that the average trade elasticity is the same between models. But I find that increasing $\gamma$ does little to change the aggregate effects of a policy. It induces a larger trade response but because goods are more substitutable, the trade response matters less for aggregate outcomes such as consumption or GDP.
} 
and capital deepening. If a static model was constrained to match the export response of a dynamic model, which is consistent with data, it would exhibit much lower gains from the liberalization since trade would grow much more slowly.

\subsection{Other key drivers}

I consider several other variations of the model that abstract from certain features to identify key drivers of the results. Among the most important components in the model are the firmlevel exporting decision (i.e. having the extensive margin in the exporting equation). A Krugman-like model where all firms export reduces welfare gains, mostly because the trade response for all countries does not grow over time. Assuming iceberg costs are uniform across all goods also lowers welfare gains as trade becomes less intensive in capital goods so there is less capital deepening after the liberalization. Finally, trade imbalances in transition seem to be relatively unimportant: assuming exogenous imbalances fixed to their steady state value results in only small changes to dynamics and welfare. Details are provided in Appendix F.

\section{Conclusion}

In this paper, I introduced a multi-country dynamic model useful for evaluating the aggregate effects of trade policy. It explains variation in both the relative size and speed of trade adjustments across destinations that we see in the data while preserving the simple IRBC framework often used for quantitative analysis. As the model is quite tractable, it can be extended to include other forms of heterogeneity such as differences across sectors or firms.

A benefit of the model is that firm decisions respond to expected future policy, opening the door for global analysis of anticipated policy such as expected future trade agreements, or temporary policy such as antidumping duties. It can also be used to study events like the U.S.-China trade war as firms make decisions about exporting that depend on how permanent they believe the trade war will be. Anticipation of future trade agreements is analyzed in a two-country model with forward-looking exporters in Alessandria and Mix (2019). I leave the analysis of temporary or expected temporary policy to future research. 


\section{References}

Alessandria, G. and Choi, H. (2007). Do sunk costs of exporting matter for net export dynamics? The Quarterly Journal of Economics, 122(1):289-336.

Alessandria, G. and Choi, H. (2014). Establishment heterogeneity, exporter dynamics, and the effects of trade liberalization. Journal of International Economics, 94(2):207-223.

Alessandria, G., Choi, H., and Ruhl, K. (2018). Trade adjustment dynamics and the welfare gains from trade. Working Paper 20663, National Bureau of Economic Research.

Alessandria, G. and Mix, C. (2019). Trade policy is real news: A quantitative analysis of past, present, and future trade costs. Mimeo, University of Rochester.

Alessandria, G., Pratap, S., and Yue, V. Z. (2013). Export dynamics in large devaluations. Mimeo.

Alvarez, F. (2017). Capital accumulation and international trade. Journal of Monetary Economics, 91:1-18.

Anderson, J. E. and Van Wincoop, E. (2003). Gravity with gravitas: A solution to the border puzzle. American Economic Review, 93(1):170-192.

Backus, D. K., Kehoe, P. J., and Kydland, F. E. (1992). International real business cycles. Journal of Political Economy, 100(4):745-775.

Baier, S. L. and Bergstrand, J. H. (2007). Do free trade agreements actually increase members' international trade? Journal of International Economics, 71(1):72-95.

Caliendo, L., Dvorkin, M., and Parro, F. (2019). Trade and labor market dynamics: General equilibrium analysis of the china trade shock. Econometrica, 87(3):741-835.

Caliendo, L. and Parro, F. (2015). Estimates of the trade and welfare effects of nafta. The Review of Economic Studies, 82(1):1-44.

Das, S., Roberts, M. J., and Tybout, J. R. (2007). Market entry costs, producer heterogeneity, and export dynamics. Econometrica, 75(3):837-873.

Dix-Carneiro, R. (2014). Trade liberalization and labor market dynamics. Econometrica, $82(3): 825-885$.

Eaton, J. and Kortum, S. (2002). Technology, geography, and trade. Econometrica, 70(5):1741-1779.

Eaton, J., Kortum, S., Neiman, B., and Romalis, J. (2016). Trade and the global recession. The American Economic Review, 106(11):3401-3438.

Fernandes, A., Freund, C., and Pierola, M. (2016). Exporter behavior, country size and stage of development: Evidence from the exporter dynamics database. Journal of Development Economics, 119(2):121-137. 
Fitzgerald, D. (2012). Trade costs, asset market frictions, and risk sharing. American Economic Review, 102(6):2700-2733.

Ghironi, F. and Melitz, M. (2005). International trade and macroeconomic dynamics with heterogeneous firms. Quarterly Journal of Economics, 120:865-915.

Ghironi, F. and Melitz, M. J. (2007). Trade flow dynamics with heterogeneous firms. American Economic Review, 97(2):356-361.

Jung, B. (2012). Gradualism and dynamic trade adjustment: Revisiting the pro-trade effect of free trade agreements. Economics Letters, 115(1):63-66.

McCallum, A. H. (2015). The structure of export entry costs. Mimeo, Federal Reserve Board.

Melitz, M. J. (2003). The impact of trade on intra-industry reallocations and aggregate industry productivity. Econometrica, 71(6):1695-1725.

Monarch, R. and Schmidt-Eisenlohr, T. (2017). Learning and the value of trade relationships. Working Paper 1218, FRB International Finance Discussion Paper.

Morales, E., Sheu, G., and Zahler, A. (2019). Extended gravity. The Review of Economic Studies, 86(6):2668-2712.

Ravikumar, B., Santacreu, A. M., and Sposi, M. (2019). Capital accumulation and dynamic gains from trade. Journal of International Economics, 119:93-110.

Reyes-Heroles, R. (2016). The role of trade costs in the surge of trade imbalances. Mimeo, Princeton University.

Ruhl, K. J. and Willis, J. L. (2017). New exporter dynamics. International Economic Review, 58(3):703-726.

Steinberg, J. B. (2019). Brexit and the macroeconomic impact of trade policy uncertainty. Journal of International Economics, 117:175-195. 


\section{A Tables}

\begin{tabular}{|c|cccc|cccc|}
\hline & \multicolumn{7}{|c|}{ Dependent Variable } \\
\hline & \multicolumn{7}{|c|}{ Incumbent Exporter Share } & \multicolumn{3}{c|}{ Incumbent Export Share } \\
\hline $\log \left(\right.$ exports $\left._{\text {ijt }}\right)$ & 0.012 & 0.011 & -0.002 & 0.023 & 0.038 & 0.037 & 0.027 & 0.049 \\
(t-statistic) & $(8.26)$ & $(8.28)$ & $(-0.64)$ & $(11.7)$ & $(14.64)$ & $(14.10)$ & $(2.57)$ & $(16.1)$ \\
& & & & & & & & \\
Year FE & No & Yes & Yes & No & No & Yes & Yes & No \\
Destination FE & No & No & Yes & No & No & No & Yes & No \\
Threshold & NA & NA & NA & $\$ 100,000$ & NA & NA & NA & $\$ 100,000$ \\
$\mathrm{R}^{2}$ & 0.08 & 0.20 & 0.68 & 0.15 & 0.21 & 0.22 & 0.37 & 0.26 \\
\hline
\end{tabular}

Table 1: Regression results confirming the positive relationship between incumbent shares and total exports. Number of observations $=792$. 


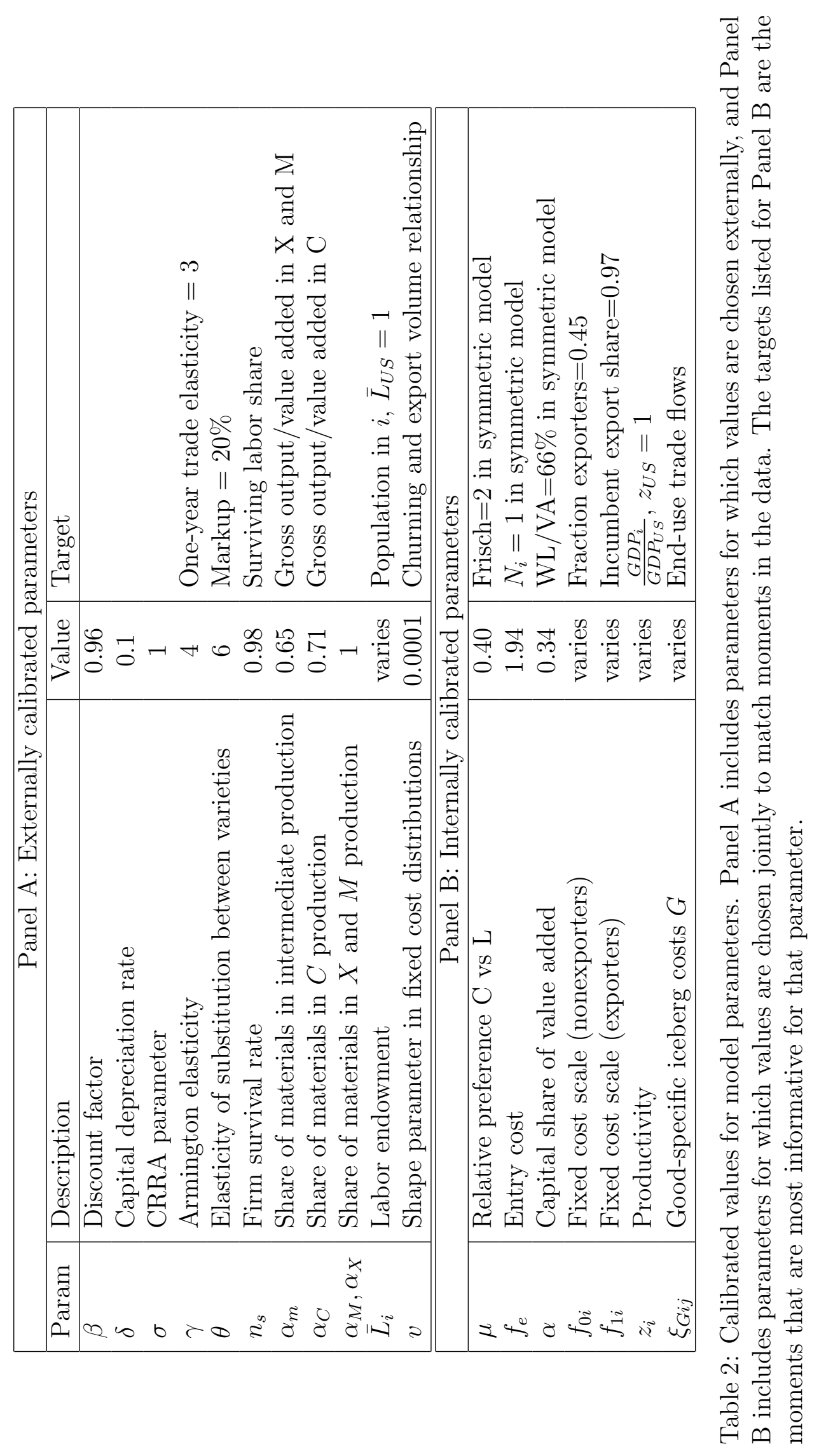




\begin{tabular}{|c|c|c|}
\hline Model & $\ln E X_{i j, 10}-\ln E X_{i j, 0}$ & $\ln E X_{i j, L R}-\ln E X_{i j, 0}$ \\
\hline Benchmark & $-4.5(-21.9)$ & $-3.7(-9.3)$ \\
Uniform churning $(\mathrm{v}=4)$ & $-0.1(-3.5)$ & $-0.4(-5.7)$ \\
Static Exporting & $-0.1(-2.5)$ & $-0.1(-1.9)$ \\
All firms export & $+0.0(0.4)$ & $+0.0(0.7)$ \\
\hline
\end{tabular}

Table 3: Coefficients from the regressions on the model simulation as specified in Section 5 . Values in parenthesis are the t-statistics of the coefficient.

\begin{tabular}{|c|c|c|c|}
\hline \multicolumn{4}{|c|}{ Impulse Response Functions } \\
\hline & Baier-Bergstrand & Minor & Major \\
\hline$I R F_{0}:$ 0-4 years & 33.5 & 34.3 & 7.7 \\
& $(7.0)$ & $(6.4)$ & $(1.4)$ \\
$I R F_{1}: 5$-9 years & 64.3 & 65.0 & 24.7 \\
& $(11.3)$ & $(9.1)$ & $(3.8)$ \\
$I R F_{2}: 9+$ years & 88.4 & 82.5 & 47.1 \\
& $(13.0)$ & $(8.7)$ & $(6.1)$ \\
\hline \hline \multicolumn{3}{|c|}{ Wald Tests } \\
\hline \multicolumn{4}{|c|}{ Null Hypothesis } \\
$I R F_{0, \text { Major }}=I R F_{0, \text { Minor }}$ & 0.000 \\
$I R F_{1, \text { Major }}=I R F_{1, \text { Minor }}$ & 0.000 \\
$I R F_{2, \text { Major }}=I R F_{2, \text { Minor }}$ & 0.002 \\
\hline
\end{tabular}

Table 4: The top panel shows impulse responses (in log points) from the original BaierBergstrand regression in column 1 and the separate impulse responses for major and minor export partners in the regression with an interaction term as described in Section 5. Values in parenthese are the z-values for each estimate. Values in parenthesis are the z-statistics for each coefficient. The bottom panel shows the results of several Wald tests on null hypotheses relevant to model predictions.

\begin{tabular}{c|c|c|c} 
Country & $\bar{\tau}_{j}(\%)$ & $\tau_{S E}(\%)$ & $\tau_{E E}(\%)$ \\
\hline U.S. & 2.4 & 0.18 & 0.14 \\
NAFTA & 2.5 & 0.20 & 0.17 \\
EU & 5.3 & 0.33 & 0.39 \\
China & 6.7 & 0.51 & 0.69 \\
East Asia & 2.7 & 0.69 & 0.38 \\
RoW & 6.1 & 0.62 & 0.66 \\
\hline
\end{tabular}

Table 5: $\bar{\tau}_{j}$ for each country is the tariff that a region charges on all regions with which there is no free trade agreement in the model. $\tau_{S E}$ and $\tau_{E E}$ are the average tariffs faced by consumers in each country on their sales or expenditure, respectively. 


\begin{tabular}{c|c|c|c|c} 
Region & Measure & Benchmark & Uniform Churning & Static Exporter \\
\hline US & $\eta$ & 0.49 & 0.42 & 0.49 \\
& $\Delta \bar{B} / Y^{*}$ & 6.2 & 6.1 & 3.7 \\
NAFTA & $\eta$ & 0.62 & 0.53 & 0.56 \\
& $\Delta \bar{B} / Y^{*}$ & 6.4 & 4.2 & 1.3 \\
EU & $\eta$ & 0.99 & 0.86 & 1.05 \\
& $\Delta \bar{B} / Y^{*}$ & 6.2 & 3.8 & 0.9 \\
China & $\eta$ & 2.04 & 1.64 & 1.95 \\
& $\Delta \bar{B} / Y^{*}$ & -9.4 & -7.0 & -2.3 \\
East Asia & $\eta$ & 1.91 & 1.65 & 1.92 \\
& $\Delta \bar{B} / Y^{*}$ & -2.2 & -0.4 & 0.6 \\
RoW & $\eta$ & 1.95 & 1.69 & 2.06 \\
& $\Delta \bar{B} / Y^{*}$ & -5.7 & -5.2 & -3.0 \\
\hline \hline
\end{tabular}

Table 6: Welfare gains and change in steady state net foreign assets from the trade liberalization. 


\section{B Figures}
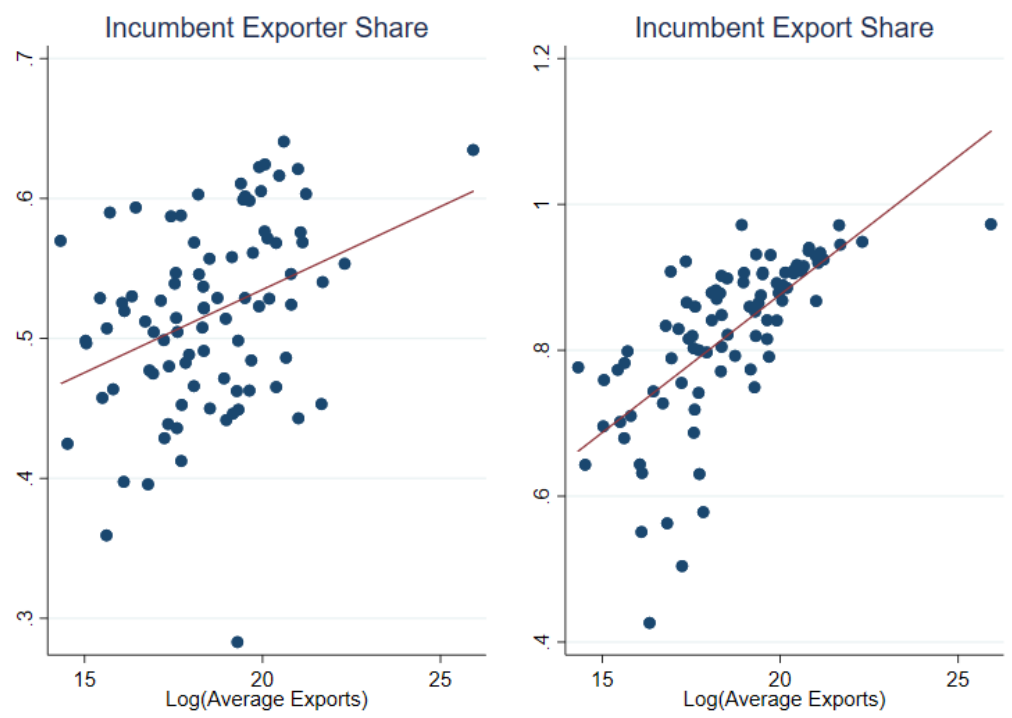

Figure 1: Incumbent shares and total export volume are positively correlated. Each dot represents a destination. The $\mathrm{x}$-axis is the $\log$ of average exports from Mexico to that destination from 2001 to 2009. The y-axes are the destination-specific incumbent share defined in Section 2, export-weighted over all years.
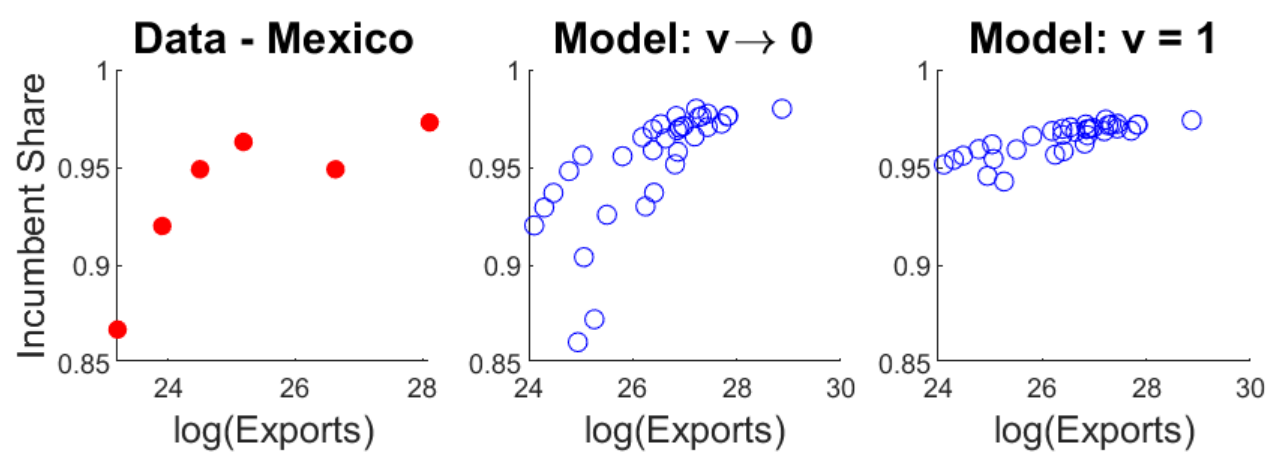

Figure 2: Incumbent shares and total export volume in the Mexican data and the model. Each dot in the model figures represents a country pair in steady state. 

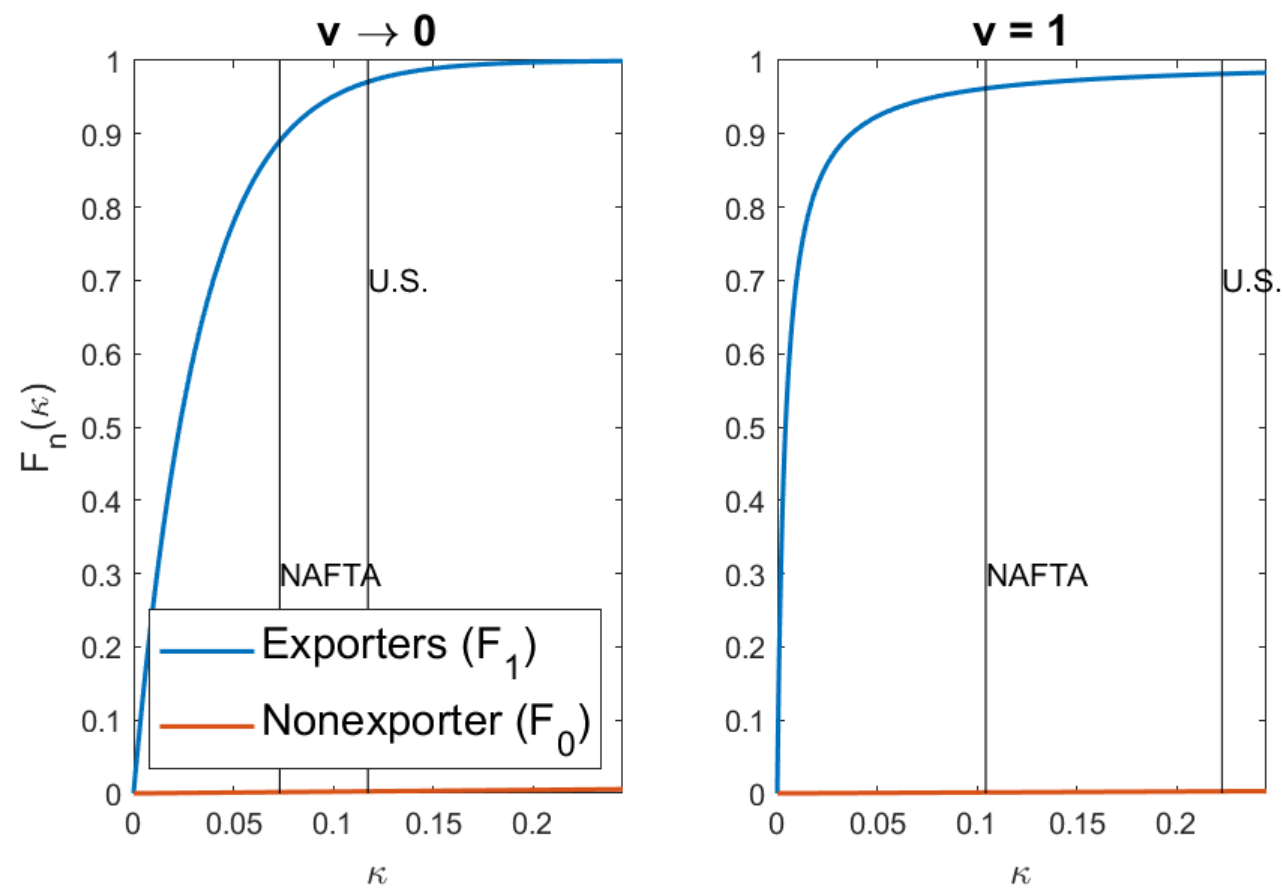

Figure 3: Exporter and nonexporter fixed cost distributions for firms in Europe with exporter thresholds for NAFTA and the U.S. Left panel is for low $v$ and right panel is for high $v$.

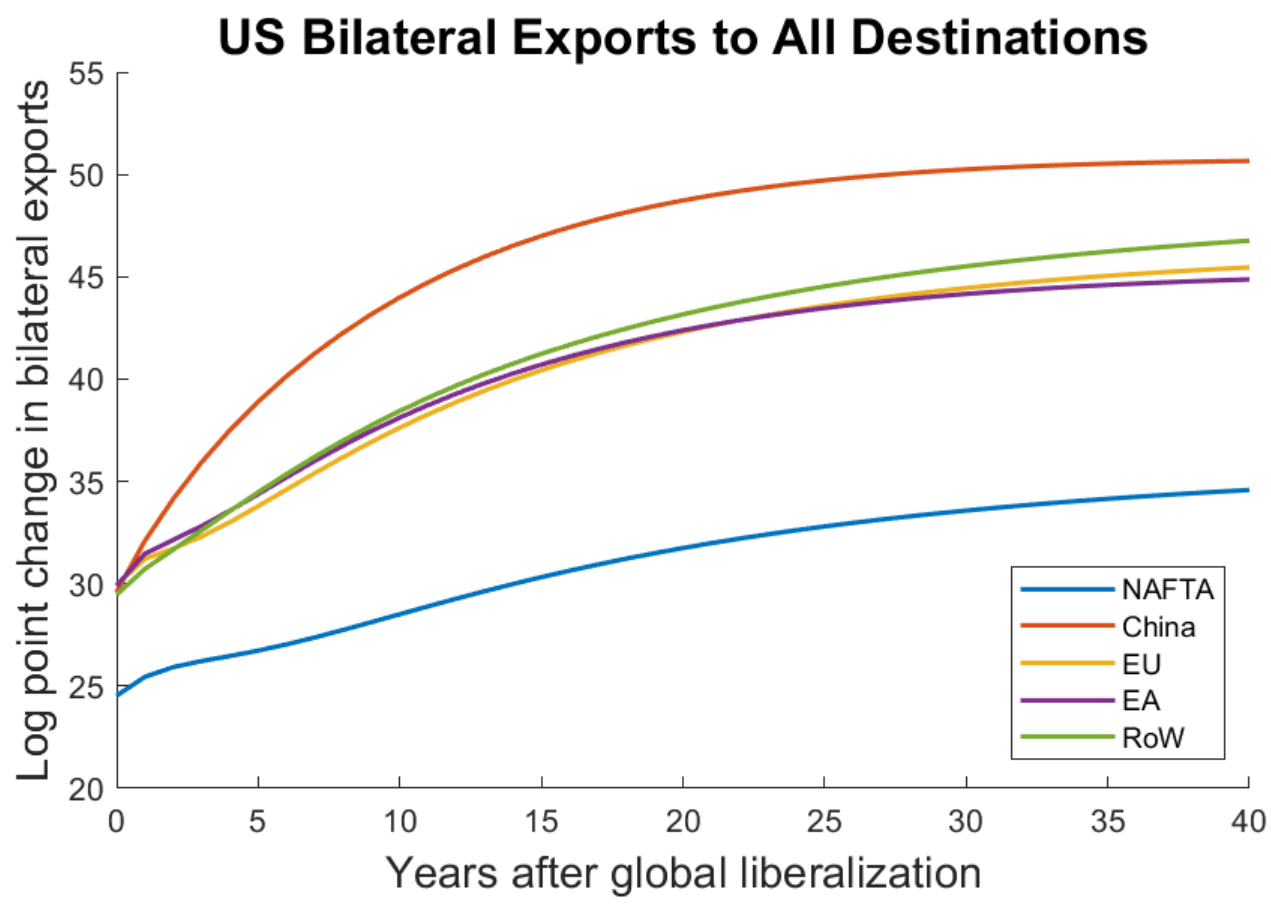

Figure 4: U.S. Bilateral exports to all destinations after a global liberalization of $5 \%$ tariffs. 

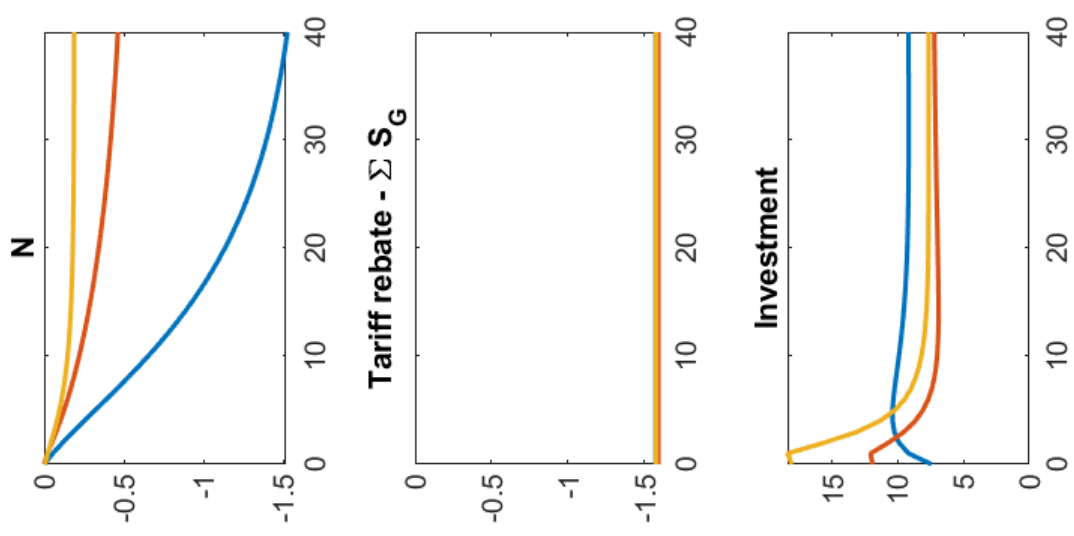

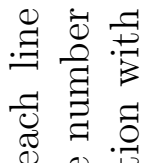
\& की

응 0

荘壱

寻

过苞

.$\exists 0$

正

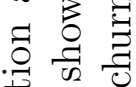

之

尝完
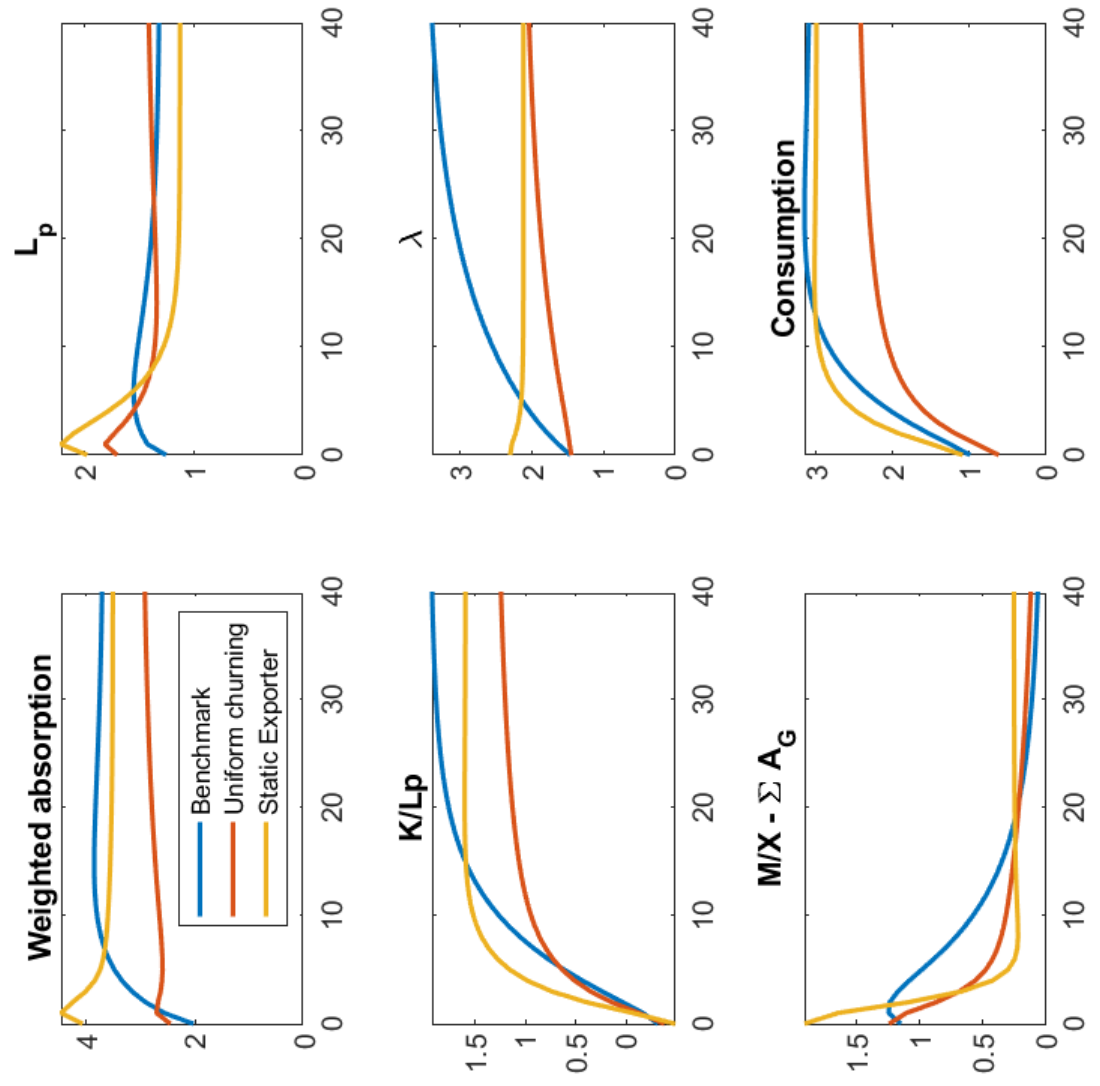

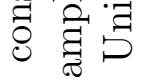

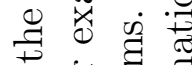

-

पै山 की

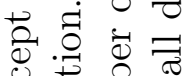

逮节

되

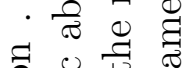

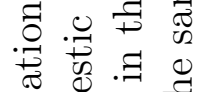

공

包

늘

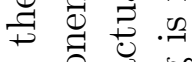

은

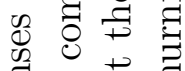

귱 동 궁

की छे हाँ

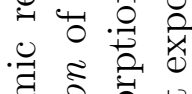

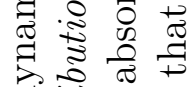

谞

丞

$\exists \mathcal{O}$

ठ

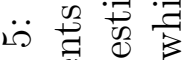

ठै छี वृ

कृ

玨? 


\section{Exporter Dynamics Database - Panel Results}

The Exporter Dynamics Database includes destination-level summary statistics on exporters in 68 countries. The panel is not balanced as the data for each country is available in different years. For each source-destination-year triple, the data report the number of exporters, mean exports per exporter (as long as the number of exporters is sufficiently high to avoid confidentiality issues), the number of incumbent exporters in the destination, and the mean exports per incumbent exporter. Using these statistics, we can get the source-destinationyear incumbent exporter share and the incumbent export share as

$$
\text { inc }_{\text {sdt }}^{n}=\frac{\text { \#incumbents }_{\text {sdt }}}{\# \text { exporters } s_{\text {sdt }}} \quad \text { and } \quad \text { inc }_{\text {sdt }}^{x}=\frac{\text { \#incumbent }_{\text {sdt }} \times \overline{\text { exports }}_{\text {incumbents }, \text { sdt }}}{\text { \#exporter } s_{\text {sdt }} \times \overline{\text { exports }}_{\text {exporters }, \text { sdt }}}
$$

where $\overline{\text { exports }}_{x, s d t}$ is the mean exports of group $x$ from source country $s$ to destination $d$ in year $t$.

The data are available for three subsets of the universe of exporters to a destination: all exporters to the destination, exporters that export more than $\$ 1,000$ to the destination, and exporters in the manufacturing sector. I calculate the incumbent shares for all three subsets of the data and estimate the following regression:

$$
\text { inc }_{s d t}=\beta \ln \text { exports }_{s d t}+\gamma_{s t}+\gamma_{d t}+\varepsilon_{s d t} .
$$

When the number of exporters is low, even one entrant has large effects on the incumbent share. To address this issue, I remove all country pairs for which the total number of exporters is below 50 for any year. When the fixed effects terms are included in the regressions, I drop all singleton observations.

Table 7 shows the results from the panel regressions. The coefficients for each type of incumbent share are positive and highly significant in all three subsets of the data, confirming the positive relationship between churning and export volume. Even without any fixed effects, export volume explains between 18 and 29 percent of the variation in incumbent shares. The relationship is robust to adding source-year and destination-year fixed effects separately so the variation among country pairs is the key variation for identification, not variation across sources or destinations. 


\begin{tabular}{|c|c|c|c|c|}
\hline \multicolumn{5}{|c|}{ All exporters } \\
\hline & \multicolumn{2}{|c|}{ Incumbent Exporter Share } & \multicolumn{2}{|c|}{ Incumbent Export Share } \\
\hline $\begin{array}{c}\log \left(\text { exports }_{i j t}\right) \\
\text { (t-statistic) }\end{array}$ & $\begin{array}{l}0.031 \\
(91.8)\end{array}$ & $\begin{array}{l}0.035 \\
(95.7)\end{array}$ & $\begin{array}{l}0.033 \\
(72.6)\end{array}$ & $\begin{array}{l}0.036 \\
(58.8)\end{array}$ \\
\hline Source-Year and Dest-Year FE & No & Yes & No & Yes \\
\hline $\mathrm{R}^{2}$ & 0.29 & 0.70 & 0.20 & 0.48 \\
\hline $\mathrm{N}$ & 21,030 & 20,561 & 21,004 & 20,538 \\
\hline \multicolumn{5}{|c|}{$\begin{array}{c}\text { All exporters with exports } \geq \$ 1,000 \\
\end{array}$} \\
\hline & \multicolumn{2}{|c|}{ Incumbent Exporter Share } & \multicolumn{2}{|c|}{ Incumbent Export Share } \\
\hline $\begin{array}{c}\log \left(\text { exports }_{i j t}\right) \\
\text { (t-statistic) }\end{array}$ & $\begin{array}{l}0.028 \\
(71.6)\end{array}$ & $\begin{array}{l}0.033 \\
(79.9)\end{array}$ & $\begin{array}{l}0.034 \\
(63.0)\end{array}$ & $\begin{array}{l}0.038 \\
(55.0)\end{array}$ \\
\hline Source-Year and Dest-Year FE & No & Yes & No & Yes \\
\hline $\mathrm{R}^{2}$ & 0.23 & 0.68 & 0.19 & 0.49 \\
\hline $\mathrm{N}$ & 17,085 & 16,544 & 17,067 & 16,527 \\
\hline \multicolumn{5}{|c|}{ Manufacturing sectors only } \\
\hline & \multicolumn{2}{|c|}{ Incumbent Exporter Share } & \multicolumn{2}{|c|}{ Incumbent Export Share } \\
\hline $\begin{array}{c}\log \left(\text { exports }_{i j t}\right) \\
\text { (t-statistic) }\end{array}$ & $\begin{array}{l}0.027 \\
(66.4)\end{array}$ & $\begin{array}{l}0.034 \\
(77.1)\end{array}$ & $\begin{array}{l}0.034 \\
(59.5)\end{array}$ & $\begin{array}{l}0.037 \\
(51.0)\end{array}$ \\
\hline Source-Year and Dest-Year FE & No & Yes & No & Yes \\
\hline $\mathrm{R}^{2}$ & 0.22 & 0.67 & 0.19 & 0.49 \\
\hline $\mathrm{N}$ & 15,894 & 15,341 & 15,883 & 15,331 \\
\hline
\end{tabular}

Table 7: Regression results confirming the positive relationship between incumbent shares and total exports.

\section{End-Use Trade}

I gather UN Comtrade data on bilateral trade by Broad Economic Categories (BEC) for the six regions in the model. Trade that is not specified $\left(\mathrm{BEC}=7^{*}\right)$ and trade in petroleum $\left(\mathrm{BEC}=321^{*}\right)$ are excluded. The remaining BEC classifications are split into capital, intermediate, and consumption goods as suggested by UN Comtrade in the following way:

\section{Capital goods:}

- $41^{*}$ Capital goods (except transport equipment)

- 521* Transport equipment, industrial

\section{Intermediate goods:}


- $111^{*}$ Food and beverages, primary, mainly for industry

- 121* Food and beverages, processed, mainly for industry

- $21^{*}$ Industrial supplies not elsewhere specified, primary

- $22 *$ Industrial supplies not elsewhere specified, processed

- 31* Fuels and lubricants, primary

- $322^{*}$ Fuels and lubricants, processed (other than motor spirit)

- $42^{*}$ Parts and accessories of capital goods (except transport equipment)

- 53* Parts and accessories of transport equipment

\section{Consumer goods:}

- $112^{*}$ Food and beverages, primary, mainly for household consumption

- $122^{*}$ Food and beverages, processed, mainly for household consumption

- $522^{*}$ Transport equipment, non-industrial

- 61* Consumer goods not elsewhere specified, durable

- $62^{*}$ Consumer goods not elsewhere specified, semi-durable

- 63* Consumer goods not elsewhere specified, non-durable

The sum over each category in capital goods, for instance, represents aggregate trade in capital goods.

\section{E Decomposition of Absorption and Steady State Wel- fareN}

In this section, I show how to construct a decomposition of either weighted absorption of steady state welfare in the model presented in this paper. First, recall that since all firms are homogeneous in productivity, we have

$$
p_{i j}(f)=\frac{\theta M C_{i}}{\theta-1},
$$


so that the price of an intermediate good depends only upon the marginal cost of producing intermediate goods in the source country. The price of a bundle of goods sent from country $i$ to country $j$ is

$$
P_{i j}=\left(\int p_{i j}(f) d f^{1-\theta}\right)^{\frac{1}{1-\theta}}=N_{i j}^{\frac{1}{1-\theta}} \frac{\theta M C_{i}}{\theta-1}
$$

and the price of a bundle of intermediates used in production of final good $G \in\{C, X, M\}$ in country $j$ is

$$
\tilde{P}_{G j}^{1-\gamma}=\sum_{i} \omega_{G i j}\left(\tau_{i j} P_{i j}\right)^{1-\gamma}=\sum_{i} \omega_{G i j} \tau_{i j}^{1-\gamma} N_{i j}^{\frac{1-\gamma}{1-\theta}}\left(\frac{\theta M C_{i}}{\theta-1}\right)^{1-\gamma}
$$

It will be useful to rewrite this equation as the product of a country $j$ term and a term that summarizes the relative efficiency of other markets in producing for country $j$ :

$$
\tilde{P}_{G j}^{1-\gamma}=\left(\frac{\theta M C_{j}}{\theta-1}\right)^{1-\gamma} \omega_{G j j} N_{j}^{\frac{1-\gamma}{1-\theta}} \sum_{i} \frac{\omega_{G i j} \tau_{i j}^{1-\gamma}}{\omega_{G j j}}\left(\frac{N_{i}}{N_{j}}\right)^{\frac{1-\gamma}{1-\theta}}\left(\frac{N_{i j}}{N_{i}}\right)^{\frac{1-\gamma}{1-\theta}}\left(\frac{M C_{i}}{M C_{j}}\right)^{1-\gamma} .
$$

We can write the demand for an individual firm's good as follows:

$$
y_{i}(f)=\sum_{j} \sum_{G} y_{i j}^{G}(f)=\sum_{j} p_{i j}(f)^{-\theta} P_{i j}^{\theta-\gamma} \tau_{i j}^{-\gamma} \sum_{G} \omega_{G i j} \tilde{P}_{G j}^{\gamma-1} \tilde{E}_{G j}
$$

where $\tilde{E}_{G j}$ is equal to the total expenditure in country $j$ on the intermediate component of final good $G$ 's production $\tilde{P}_{j} \tilde{G}_{j}$. Plugging in the derived value for prices $p_{i j}(f), P_{i j}$ and $\tilde{P}_{G j}$ and then integrating over firms yields

$$
y_{i}=\frac{\theta-1}{\theta M C_{i}} \sum_{G} \frac{\tilde{E}_{G i} A_{G i}}{S_{G i}}
$$

where I have defined

$$
A_{G i}=\frac{\sum_{j} \frac{\omega_{G i j} \tau_{i j}^{-\theta}}{\omega_{G i i}}\left(\frac{N_{i j}}{N_{i}}\right)^{\frac{1-\gamma}{1-\theta}}\left(\frac{\tilde{P}_{G j}}{\tilde{P}_{G i}}\right)^{\gamma-1} \frac{\tilde{E}_{G j}}{\tilde{E}_{G i}}}{\sum_{j} \frac{\omega_{G j i} \tau_{j i}^{-\gamma}}{\omega_{G i i}}\left(\frac{N_{j}}{N_{i}}\right)^{\frac{1-\gamma}{1-\theta}}\left(\frac{N_{j i}}{N_{j}}\right)^{\frac{1-\gamma}{1-\theta}}\left(\frac{M C_{j}}{M C_{i}}\right)^{1-\gamma}}
$$


and

$$
S_{G i}=\frac{\sum_{j} \frac{\omega_{G j i} \tau_{j i}^{1-\gamma}}{\omega_{G i i}}\left(\frac{N_{j}}{N_{i}}\right)^{\frac{1-\gamma}{1-\theta}}\left(\frac{N_{j i}}{N_{j}}\right)^{\frac{1-\gamma}{1-\theta}}\left(\frac{M C_{j}}{M C_{i}}\right)^{1-\gamma}}{\sum_{j} \frac{\omega_{G j i} \tau_{j i}^{-\gamma}}{\omega_{G i i}}\left(\frac{N_{j}}{N_{i}}\right)^{\frac{1-\gamma}{1-\theta}}\left(\frac{N_{j i}}{N_{j}}\right)^{\frac{1-\gamma}{1-\theta}}\left(\frac{M C_{j}}{M C_{i}}\right)^{1-\gamma}} .
$$

$A_{G i}$ and $S_{G i}$ both have very straightforward interpretations. To see this, we first derive expressions for aggregate export revenue for good $G$ intermediates $E X_{R G}$, expenditure on domestically produced intermediates $D_{R G}$, import expenditure $I M_{G}$, and the aggregate revenue of foreign firms exporting to the United States (which I call import revenue) $I M_{R G}$.

$$
\begin{aligned}
& E X_{R G i}=\sum_{j \neq i} \int p_{i j}(f) G_{i j}(f) d f=\left(\frac{\theta M C_{i}}{\theta-1}\right)^{1-\gamma} \sum_{j \neq i} N_{i j}^{\frac{1-\gamma}{1-\theta}} \omega_{G i j} \tau_{i j}^{-\gamma} \tilde{P}_{G j}^{\gamma-1} \tilde{E}_{G j} \\
& D_{R G i}=\left(\frac{\theta M C_{i}}{\theta-1}\right)^{1-\gamma} N_{i}^{\frac{1-\gamma}{1-\theta}} \omega_{G i i} \tilde{P}_{G i}^{\gamma-1} \tilde{E}_{G i} \\
& I M_{G i}=\tilde{P}_{G i}^{\gamma-1} \tilde{E}_{G i} \sum_{j \neq i} N_{j i}^{\frac{1-\gamma}{1-\theta}} \omega_{G j i} \tau_{j i}^{1-\gamma}\left(\frac{\theta M C_{j}}{\theta-1}\right)^{1-\gamma} \\
& I M_{R i}=\tilde{P}_{G i}^{\gamma-1} \tilde{E}_{G i} \sum_{j \neq i} N_{j i}^{\frac{1-\gamma}{1-\theta}} \omega_{G j i} \tau_{j i}^{-\gamma}\left(\frac{\theta M C_{j}}{\theta-1}\right)^{1-\gamma} .
\end{aligned}
$$

Then we can rewrite $A_{G i}$ and $S_{G i}$ as

$$
A_{G i}=\frac{1+\frac{E X_{R G i}}{D_{R G i}}}{1+\frac{I M_{R G i} i}{D_{R G i}}} \quad \text { and } \quad S_{G i}=\frac{1+\frac{I M_{G i}}{D_{R G i}}}{1+\frac{I M_{R G i}}{D_{R G i}}}
$$

(At this point, we can drop the country subscripts unless necessary.) Thus, $A_{G}$ represents the relative exporting and importing behavior of the country and $S_{G}$ represents the import weighted average of the bilateral tariffs. If we assume that trade is balanced in the initial period, then we can take the expression for $A_{G i}$ one step further to find that $\hat{A_{G}} \approx E \hat{X}_{R}-$ $I \hat{M}_{R}$ where $\hat{x}$ represents the change in $\log x$ from the initial period.

The domestic expenditure share $\lambda_{I M}$ is denoted by

$$
\lambda_{I M}=\frac{D_{R}}{D_{R}+I M}=\frac{1}{1+\frac{I M}{D_{R}}}
$$

and is familiar to readers of the literature as one of the key statistics in gains from trade formulations of the type considered by ACR (2012). Two more shares are useful here: the 
share of produced goods sold at home $\lambda_{E X R}$ and the domestic expenditure share exclusive of tariffs $\lambda_{I M R}$. We can use these shares to rewrite

$$
A_{G}=\frac{\lambda_{I M G R}}{\lambda_{E X G R}} \quad \text { and } \quad S_{G}=\frac{\lambda_{I M G R}}{\lambda_{I M G}}
$$

where the $G$ denotes that these expenditure shares are calculated within intermediate expenditures of a certain final good $G$.

Using a first order condition from the intermediate goods producers problem, we know that $l(f) W_{i}=M C_{i}\left(1-\alpha_{m}\right)(1-\alpha) y(f)$ which implies that

$$
L_{p}=\left(1-\alpha_{m}\right)(1-\alpha) \frac{\theta-1}{\theta} \frac{\tilde{P}_{C}}{W} \sum_{G} \frac{\tilde{E}_{G} A_{G}}{\tilde{P}_{C} S_{G}} \propto \frac{\tilde{P}_{C}}{W} \sum_{G} \frac{\tilde{E}_{G} A_{G}}{\tilde{P}_{C} S_{G}}
$$

where $L_{p}$ denotes the labor used in production of intermediate goods. Taking a linear approximation around the initial steady state we can write the equation in log changes from the initial steady state as

$$
\hat{L}_{p} \approx \hat{\tilde{P}}_{C}-\hat{W}+\tilde{s}_{C} \hat{\tilde{C}}+\tilde{s}_{I}\left(\hat{\tilde{P}}_{I}-\hat{\tilde{P}}_{C}+\hat{\tilde{I}}\right)+\tilde{s}_{M}\left(\hat{\tilde{P}}_{M}-\hat{\tilde{P}}_{C}+\hat{\tilde{M}}\right)+\sum_{G} \tilde{s}_{G}\left(\hat{A}_{G}-\hat{S}_{G}\right)
$$

where $\tilde{s}_{G}$ is the steady state value of $\frac{\alpha_{G} \tilde{E}_{G} A_{G} / S_{G}}{\sum_{H} \alpha_{H} \tilde{E}_{H} A_{H} / S_{H}}$. Because the production function for final goods is Cobb-Douglas, we know that $\tilde{P}_{G} \tilde{G}=\alpha_{G} P_{G} G$. Therefore,

$$
\hat{L}_{p} \approx \hat{P}_{C}-\hat{W}+\tilde{s}_{C} \hat{C}+\tilde{s}_{I}\left(\hat{P}_{I}-\hat{P}_{C}+\hat{I}\right)+\tilde{s}_{M}\left(\hat{P}_{M}-\hat{P}_{C}+\hat{M}\right)+\sum_{G} \tilde{s}_{G}\left(\hat{A}_{G}-\hat{S}_{G}\right)
$$

Notice that if the Armington weights did not differ by goods (trade was not intensive in capital and intermediate goods), then a linear approximation would not be needed. We can also see that if (1) $\alpha_{G}=1$ for all $G$, (2) trade is balanced so that $A_{G}=1$, and (3) there are no tariffs $\left(S_{G}=1\right)$, then the shares $\tilde{s}_{G}$ are just the share of expenditure of country $i$ on final good $G$. Allowing for trade imbalances, tariffs, and labor in final goods production makes it necessary to weight the expenditure on each good by its importance in production and trade.

Using the market clearing condition for materials, we get

$$
\hat{M}+\hat{P}_{M}-\hat{P}_{C} \approx \frac{\tilde{s}_{C} \hat{C}+\tilde{s}_{I}\left(\hat{P}_{I}-\hat{P}_{C}+\hat{I}\right)+\sum_{G} \tilde{s}_{G}\left(\hat{A}_{G}-\hat{S}_{G}\right)}{1-\tilde{s}_{M}} .
$$


Defining $\hat{D A}=\left[\tilde{s}_{C} \hat{C}+\tilde{s}_{I}\left(\hat{P}_{I}-\hat{P}_{C}+\hat{I}\right)\right] /\left(1-\tilde{s}_{M}\right)$, we can substitute the market clearing condition to get

$$
\hat{D A} \approx \hat{W}-\hat{P}_{C}+\hat{L}_{p}-\sum_{G} \frac{\tilde{s}_{G}}{1-\tilde{s}_{M}}\left(\hat{A}_{G}-\hat{S}_{G}\right)
$$

We can think about $\hat{D A}$ as weighted domestic absorption where nominal investment is deflated by the price of consumption to derive real investment. This expression will be useful to understand the sources of the macroeconomic dynamics in response to changes in trade policy. It would be nice, however, to have a measure that did not depend on such a strict weighting and the incorrect deflation of nominal investment. A better measure can be found but is only useful for comparing steady state changes. By recognizing that, in steady state, $R \propto P_{I}$ and $K \propto I$, we have $R K \propto P_{I} I$. We can then use the capital market clearing condition to derive an expression for $\hat{C}^{S S}$ :

$$
\hat{C}^{S S} \approx \hat{W}^{S S}-\hat{P}_{C}^{S S}+\hat{L}_{p}^{S S}-\sum_{G} \frac{\tilde{s}_{G}}{\tilde{s}_{C}}\left(\hat{A}_{G}^{S S}-\hat{S}_{G}^{S S}\right)
$$

Notice that the expression is the same except for the scaling of the final term.

Moving forward, recall that $P_{C} \propto \tilde{P}_{C}^{\alpha_{C}} W^{1-\alpha_{C}}$ so that $\frac{W}{P_{C}} \propto\left(\frac{W}{\tilde{P}_{C}}\right)^{\alpha_{C}}$. Using our expression derived above for $\tilde{P}_{C}$, we have

$$
\frac{W}{P_{C}} \propto\left[\frac{W}{M C} N^{\frac{1}{\theta-1}} \lambda_{C}^{\frac{1}{1-\gamma}}\right]^{\alpha_{C}}
$$

where I have substituted $\lambda_{C}$ into $\tilde{P}_{C}$. Using the expression for the marginal cost, one can derive

$$
\frac{W}{M C} \propto\left(\frac{W}{\tilde{P}_{M}}\right)^{\alpha_{m}}\left(\frac{W}{R}\right)^{\alpha\left(1-\alpha_{m}\right)} \propto\left(\frac{W}{\tilde{P}_{C}}\right)^{\alpha_{m}}\left(\frac{\tilde{P}_{C}}{\tilde{P}_{M}}\right)^{\alpha_{m}}\left(\frac{K}{L_{p}}\right)^{\alpha\left(1-\alpha_{m}\right)}
$$

Now we once again use $P_{C} \propto \tilde{P}_{C}^{\alpha_{C}} W^{1-\alpha_{C}}$ as well as the expressions for prices $\tilde{P}_{M}$ and $\tilde{P}_{C}$ to get

$$
\frac{W}{M C} \propto\left(\frac{W}{P_{C}}\right)^{\frac{\alpha_{m}}{\alpha_{C}}}\left(\frac{\lambda_{C}}{\lambda_{M}}\right)^{\frac{\alpha_{m}}{\gamma-1}}\left(\frac{K}{L_{p}}\right)^{\alpha\left(1-\alpha_{m}\right)}
$$


Plugging this back into the expression for $\frac{W}{P_{C}}$, we get

$$
\begin{aligned}
\frac{W}{P_{C}} & \propto\left(\frac{W}{P_{C}}\right)^{\alpha_{m}}\left(\frac{\lambda_{C}}{\lambda_{M}}\right)^{\frac{\alpha_{m} \alpha_{C}}{\gamma-1}}\left(\frac{K}{L_{p}}\right)^{\alpha \alpha_{C}\left(1-\alpha_{m}\right)} N^{\frac{\alpha_{C}}{\theta-1}} \lambda_{C}^{\frac{\alpha_{C}}{1-\gamma}} \\
& \propto\left(\lambda_{C} \lambda_{M}^{\frac{\alpha_{m}}{1-\alpha_{m}}}\right)^{\frac{\alpha_{C}}{1-\gamma}}\left(\frac{K}{L_{p}}\right)^{\alpha \alpha_{C}} N^{\frac{\alpha_{C}}{\left(1-\alpha_{m}\right)(\theta-1)}}
\end{aligned}
$$

which we can then plug into our expressions for $\hat{D A}$ and $\hat{C}^{S S}$.

$$
\begin{aligned}
\hat{D A} \approx \frac{\alpha_{C}}{1-\gamma} & \left(\hat{\lambda}_{C}+\frac{\alpha_{m}}{1-\alpha_{m}} \hat{\lambda}_{M}\right)+\alpha \alpha_{C}\left(\hat{K}-\hat{L}_{p}\right)+\frac{\alpha_{C}}{\left(1-\alpha_{m}\right)(\theta-1)} \hat{N}+\hat{L}_{p} \\
& -\sum_{G} \frac{\tilde{s}_{G}}{1-\tilde{s}_{M}}\left(\hat{A}_{G}-\hat{S}_{G}\right) \\
\hat{C}^{S S} \approx \frac{\alpha_{C}}{1-\gamma}\left(\hat{\lambda}_{C}^{S S}+\frac{\alpha_{m}}{1-\alpha_{m}} \hat{\lambda}_{M}^{S S}\right)+\alpha \alpha_{C}\left(\hat{K}^{S S}-\hat{L}_{p}^{S S}\right)+\frac{\alpha_{C}}{\left(1-\alpha_{m}\right)(\theta-1)} \hat{N}^{S S} & \\
& +\hat{L}_{p}^{S S}-\sum_{G} \frac{\tilde{s}_{G}}{\tilde{s}_{C}}\left(\hat{A}_{G}^{S S}-\hat{S}_{G}^{S S}\right) .
\end{aligned}
$$

The decomposition for $\hat{D A}$ is used in the paper to identify key mechanisms that generate dynamics in response to trade policy. The decomposition for the steady state change in consumption brings us closer to calculating long run changes in welfare. To calculate welfare, notice that the intratemporal condition of the households problem implies

$$
1 \hat{-} L=\hat{C}-\hat{W}+\hat{P}_{C}
$$

The Cobb-Douglas utility function implies that the long run change in utility is

$$
\begin{aligned}
\hat{U}^{S S}= & \mu \hat{C}^{S S}+(1-\mu)(1 \hat{-} L)^{S S} \\
= & \hat{C}^{S S}+(1-\mu)\left(\hat{P}_{C}^{S S}-\hat{W}^{S S}\right) \\
= & \mu\left(\hat{W}^{S S}-\hat{P}_{C}^{S S}\right)+\hat{L}_{p}^{S S}-\sum_{G} \frac{\tilde{s}_{G}}{\tilde{s}_{C}}\left(\hat{A}_{G}^{S S}-\hat{S}_{G}^{S S}\right) \\
= & \frac{\alpha_{C} \mu}{1-\gamma}\left(\hat{\lambda}_{C}^{S S}+\frac{\alpha_{m}}{1-\alpha_{m}} \hat{\lambda}_{M}^{S S}\right)+\alpha \alpha_{C} \mu\left(\hat{K}^{S S}-\hat{L}_{p}^{S S}\right) \\
& \quad+\frac{\alpha_{C} \mu}{\left(1-\alpha_{m}\right)(\theta-1)} \hat{N}^{S S}+\hat{L}_{p}^{S S}-\sum_{G} \frac{\tilde{s}_{G}}{\tilde{s}_{C}}\left(\hat{A}_{G}^{S S}-\hat{S}_{G}^{S S}\right)
\end{aligned}
$$

Because utility is not cardinal, the usefulness of this decomposition is only qualitative. 
Consider instead the change in consumption that would be necessary to make one indifferent between the initial steady state and the new steady state. Essentially, it's the gain from trade assuming that the terminal steady state is obtained immediately. Call this log change in consumption $\hat{C}^{*}$. It must satisfy $\hat{U}=\mu \hat{C}^{*}$. Then we have

$$
\begin{aligned}
\hat{C}^{*}=\frac{\alpha_{C}}{1-\gamma} & \left(\hat{\lambda}_{C}^{S S}+\frac{\alpha_{m}}{1-\alpha_{m}} \hat{\lambda}_{M}^{S S}\right)+\alpha \alpha_{C}\left(\hat{K}^{S S}-\hat{L}_{p}^{S S}\right) \\
& +\frac{\alpha_{C}}{\left(1-\alpha_{m}\right)(\theta-1)} \hat{N}^{S S}+\frac{1}{\mu} \hat{L}_{p}^{S S}-\sum_{G} \frac{\tilde{s}_{G}}{\mu \tilde{S}_{C}}\left(\hat{A}_{G}^{S S}-\hat{S}_{G}^{S S}\right) .
\end{aligned}
$$

This decomposition can be used to compare long run outcomes across models, even if the calibrated preferences are not the same.

\section{E.1 Comparison to literature}

Decomposing the effects from trade is by no means a new pursuit. In this section, I compare the decompositions above with two representative decompositions from the literature: ACR (2012), and ACR (2019).

ACR (2012) shows that for a large class of static trade models, the domestic expenditure share $\lambda=\frac{D}{D+I M}$ and an estimated trade elasticity $\varepsilon$ are sufficient to calculate the welfare gains from trade $\hat{C}^{*}=-\lambda / \varepsilon$. In an Armington structure such as the basic framework of this model, the trade elasticity is $\varepsilon=\gamma-1$ and the gains are $\hat{C}^{*}=\lambda /(1-\gamma)$. This component shows up with significant changes in the first term of the above decomposition for steady state utility changes. For exposition, we can rewrite this term as

$$
\frac{\alpha_{C}}{(1-\gamma)\left(1-\alpha_{m}\right)}\left[\left(1-\alpha_{m}\right) \hat{\lambda}_{C}^{S S}+\alpha_{m} \hat{\lambda}_{M}^{S S}\right]
$$

The first difference is that $\lambda$ must now be represented as a weighted average between $\lambda_{C}$ and $\lambda_{M}$ with the weight being determined by the share of input expenditure on materials $\alpha_{m}$. The higher is this share, the more intermediates are moved around the globe before being used to create consumption or investment final goods. This makes trade in materials more important for overall welfare as the price of the final consumption good will be more heavily influence by the price of intermediates. This is also apparent in the constant that multiplies the expenditure shares; it is increasing in $\alpha_{m}$. Since trade is more intensive in materials than in consumption goods, larger $\alpha_{m}$ implies larger gains from trade.

The multiplier on trade also includes $\alpha_{C}$, the Cobb-Douglas parameter on the bundle of intermediates in the production of consumption final goods. When $\alpha_{C}<1$, changes in tariffs and trade have a smaller impact on the price of consumption goods and thus lower 
the steady state utility changes coming from changes in domestic and foreign expenditure patterns.

The model in this paper also includes several other components to the gains from trade calculation. Long run gains (or losses) can also come from changes in the number of firms, tariff revenues, trade imbalances, capital deepening, and production labor.

A similar decomposition of domestic absorption is derived in ACR (2019). Because trade composition between goods is not matched, a linear approximation is not needed and domestic absorption is simply $C+I$, rather than the more complicated weighted expression from this paper. Despite this, the two decompositions are strikingly similar. They have

$$
\left.\hat{D A}=\frac{1}{(\gamma-1)\left(1-\alpha_{m}\right)}\left(\hat{N}+\hat{\psi}_{d}-\hat{\lambda}\right)+\alpha\left(\hat{K}-\hat{L}_{p}\right)+\hat{L}_{p}-\left[S-\alpha_{m} \hat{(\theta}-1\right) / \theta\right] .
$$

ACR (2019) assumes that $\gamma=\theta$ and that firms have heterogeneous productivity with average productivity in a country denoted by $\psi_{d}$. Final goods are produced using only intermediate goods. Like this paper, they assume roundabout production so that intermediates may travel the world several times before becoming a consumption or investment good. Thus, the effect of trade is still increasing in $\alpha_{m}$. However, all goods are traded with the same share so that the contribution of trade to domestic absorption is represented by a single share $\lambda$. As in the ACR (2012) decomposition, the ACR (2019) decomposition lacks the $\alpha_{C}$ and $\mu$ scaling on several terms, reflecting the aggregation of consumption final goods and the independence of utility and leisure, respectively.

A key difference is that the ACR (2019) decomposition includes a measure of relative productivity that can change over time. Firms are homogeneous in my model, so this term does not appear. However, an analog of it exists in the fraction of firms that export, which is captured within $A_{G}$. $A_{G}$ does not enter the decomposition of ACR (2019). In general, $A_{G}$ captures the effect of asymmetries between countries in production efficiency and demand and since the ACR model is symmetric, $A_{G}=1$ for all $t$.

\section{F Decomposition of Absorption in China for other model variations}

Table 8 includes the welfare gains for several other variations of the model. All dynamics as reported in the paper for alternative models are found in Figure 6. Alternative versions of the model include:

Incumbent shares to match 5-year contribution of exporters. This version of 
the model is calibrated to match the average contribution of new exporters within the past five years to bilateral exports. In the Mexican data, firms with up to five years of tenure in a destination account for nearly $25 \%$ of total exports, which implied an incumbent share of 0.945, slightly below the benchmark model. 12 The difference makes for a quicker transition in trade, capital, trade imbalances, etc. But at the same time, the probability of becoming an exporter remains low and the influx of foreign exporters makes firm entry fall by even more than in the benchmark model, resulting in more exaggerated overshooting of absorption. One might think that the slight increase in churning would put dynamics somewhere in between the static exporter model, with high churning, and the benchmark model, with low churning. But this version of the model indicates dynamics are not linear in export churning.

Krugman-type model. In this version, all firms export $\left(f_{0}=f_{1}=0\right)$. Trade dynamics is limited to the small static response and is the same for all destinations, which limits the increase in capital. The welfare gains from this model are smaller than in the benchmark model, especially for those that gain more from the agreement.

No good-specific iceberg costs. The calibration for this model assumes $\xi_{C}=\xi_{X}=$ $\xi_{M}$. Because trade is not intensive in capital, the liberalization yields a weaker investment response and long run increases in consumption and GDP are smaller than in the benchmark model. Welfare gains are smaller for all countries.

No trade imbalances. This calibration assumes an infinite cost of adjusting the net foreign asset position. The composition of trade (and trade imbalances) among goods can change, but the overall trade imbalance is fixed at its initial level. The welfare gains are nearly identical to the benchmark model, and dynamics (shown in Appendix F for China) change only slightly. When China can borrow, it uses the extra resources to consume and invest a little more in the short run. That trade imbalances matter little for aggregate dynamics and welfare gains is consistent with the result in Ravikumar et al. (2019).

\footnotetext{
${ }^{12}$ Firms with up to five years of tenure in the model account for $14 \%$ of total exports.
} 


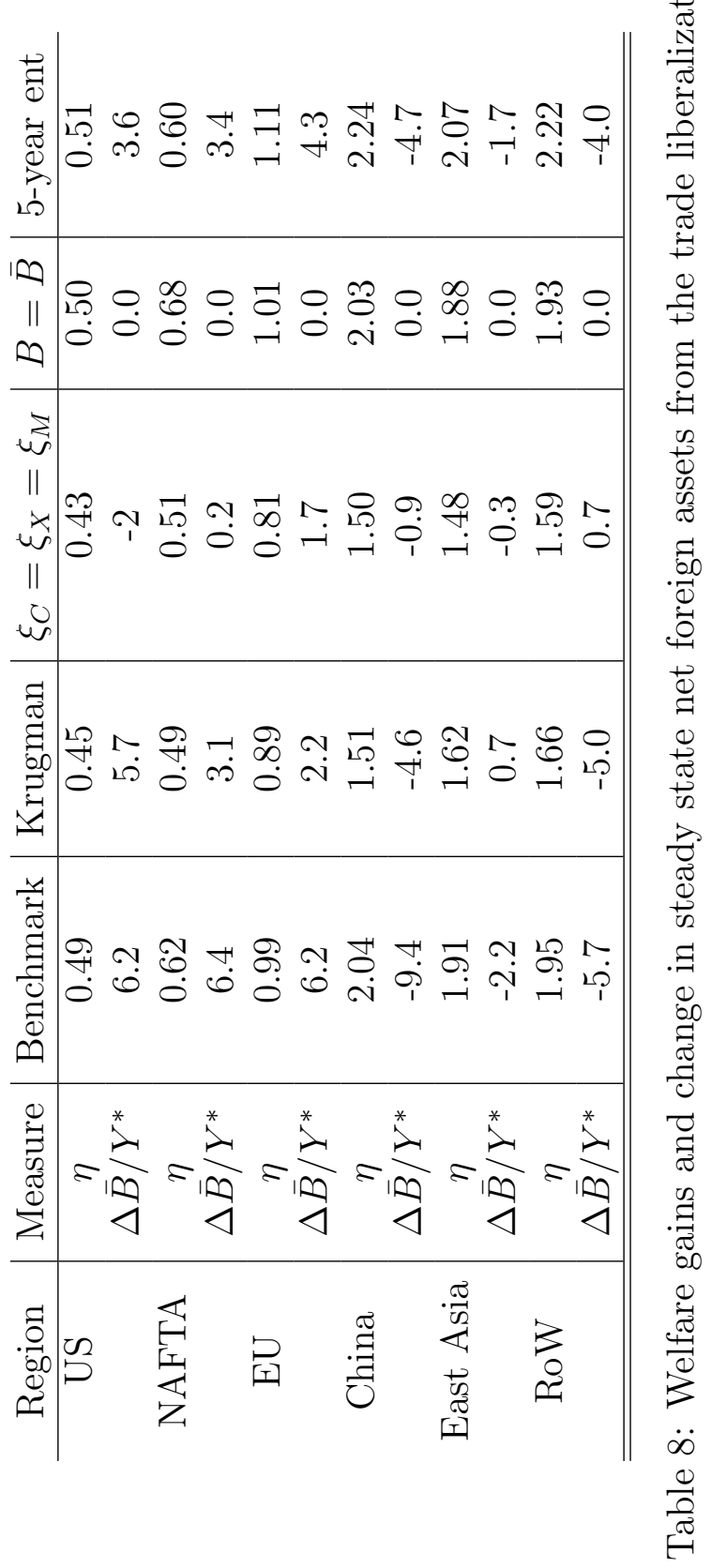



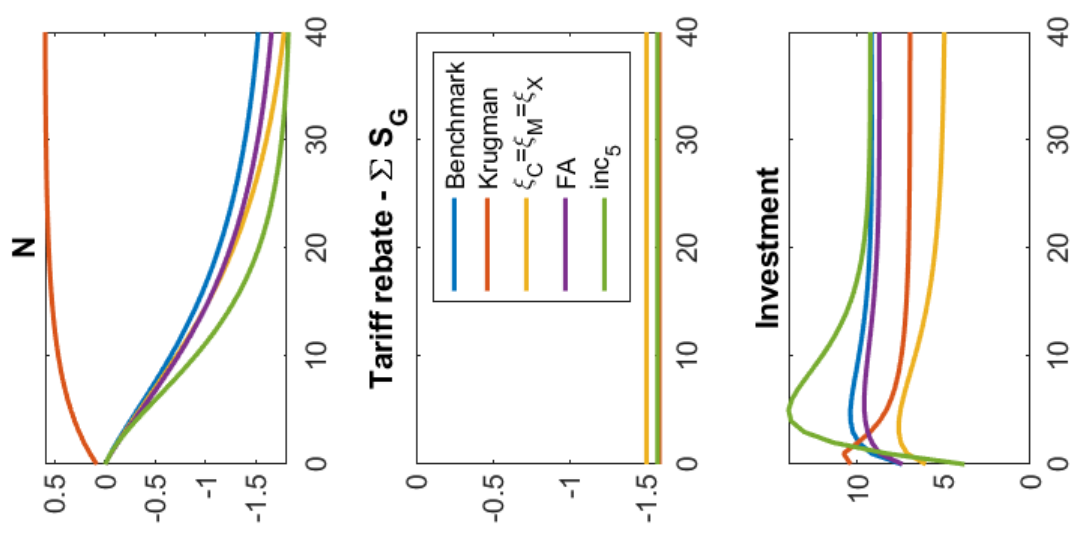

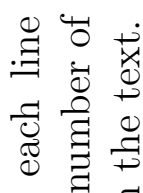

की

듬.

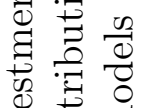

点

ஏ

형

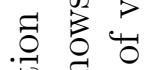

त्ञ

寻文

है
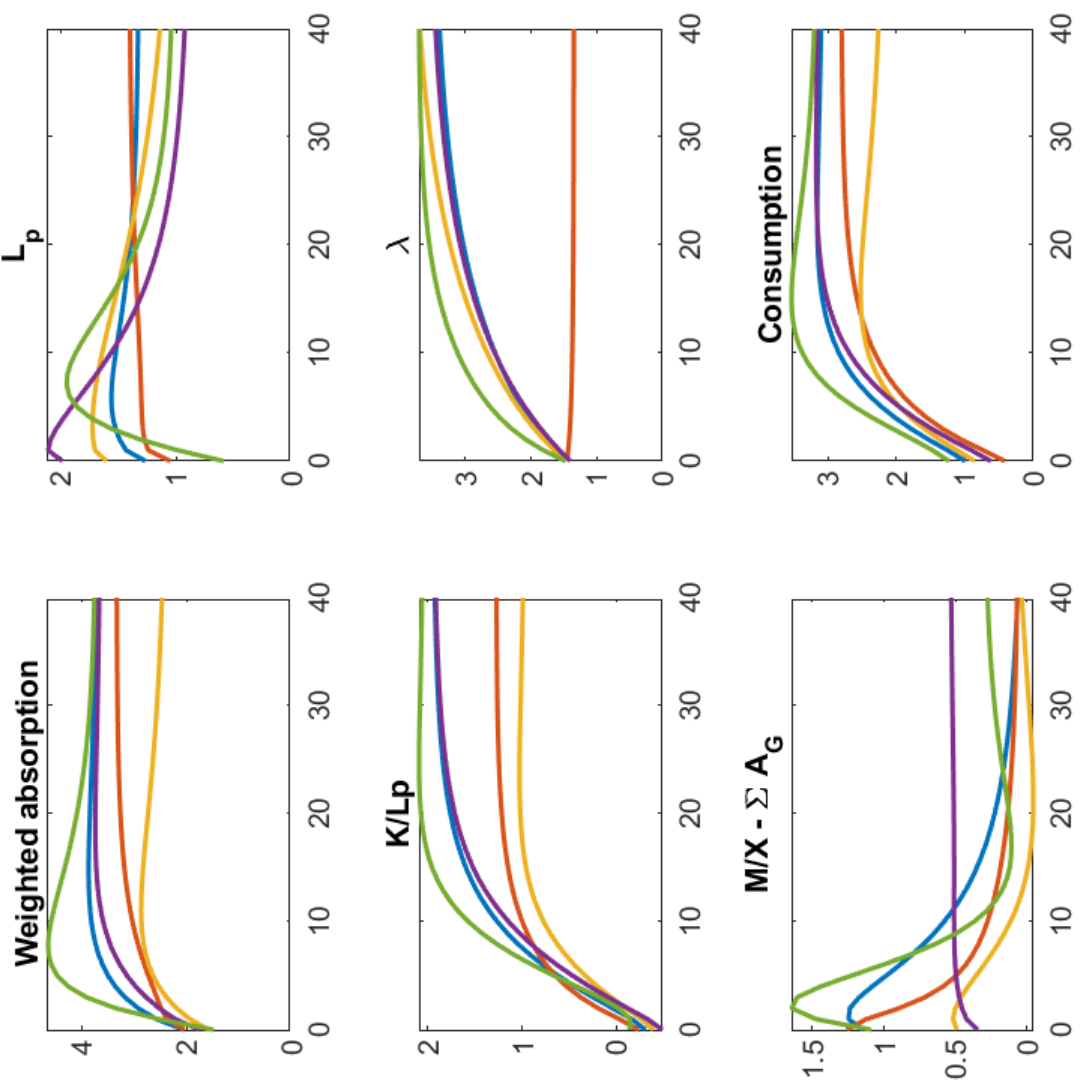

○ छ

펑

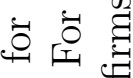

릉

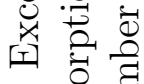

요

诂

. 코 ․․․

రิ)

$\because \stackrel{0}{\Xi}$

刍苛

$\circ$ 귱

ฆै छี

号 0

औै

들

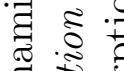

青芯

थ

光

0 品.

0

它 